\title{
Liposomes loaded with phenolic extracts of Spirulina LEB-18: Physicochemical characterization and behavior under simulated gastrointestinal conditions
}

\author{
Adriana R. Machado ${ }^{\mathrm{a}, \mathrm{b}}$, Ana C. Pinheiro ${ }^{\mathrm{b}, \mathrm{c}}$, António A. Vicente ${ }^{\mathrm{b}}$, Leonor A. Souza-Soares ${ }^{\mathrm{a}}$, \\ Miguel A. Cerqueira ${ }^{\mathrm{b}, \mathrm{d}, *}$ \\ ${ }^{a}$ Laboratório de Micotoxinas e Ciência de Alimentos, Universidade Federal do Rio Grande, Brazil, \\ ${ }^{\mathrm{b}}$ Centro de Engenharia Biológica, Universidade do Minho, Campus de Gualtar, Braga 4710-057, Portugal \\ ${ }^{\mathrm{c}}$ Instituto de Biologia Experimental e Tecnológica, Avenida da República, Quinta-do-Marquês, Estação Agronómica Nacional, Apartado 12, Oeiras 2781-901, Portugal \\ ${ }^{\mathrm{d}}$ INL - International Iberian Nanotechnology Laboratory, Av. Mestre José Veiga, Braga 4715-330, Portugal
}

\section{A R T I C L E I N F O}

\section{Keywords:}

Encapsulation

Bioactive compounds

Controlled release

Microalgae

\begin{abstract}
A B S T R A C T
Liposomes composed of rice (RL) and soybean (SL) lecithins were produced by reverse phase evaporation and used for the encapsulation of phenolic extracts from Spirulina LEB-18 (S-RL and S-SL for liposomes of rice and soybean lechitin, respectively). Liposomes were characterized in terms of size distribution, polydispersity index, and $\zeta$-potential; the chemical interactions between the phenolic compounds from Spirulina and liposomes were evaluated by Fourier Transform Infrared Spectroscopy (FTIR), and X-ray diffraction (XRD) and differential scanning calorimetry (DSC) were used to evaluate their crystallinity pattern. The release behavior of phenolic extracts was evaluated under two different $\mathrm{pH}$ conditions. Afterwards, in vitro digestibility of liposomes was evaluated in a dynamic gastrointestinal system. Liposomes exhibited high encapsulation efficiency (88.28\% and 97.35\% for S-RL and S-SL, respectively) and sizes ranging between 250 and $291 \mathrm{~nm}$, showing to be good candidates for the encapsulation of phenolic extracts obtained from microalgae. Results showed that liposomes are stable at low $\mathrm{pH}$ values and that they are able to resist to the stomach conditions but they lose their integrity under intestinal conditions. This work increases the knowledge about the effects of in vitro gastrointestinal digestion on liposomes and provides important information for the design of liposome formulations aiming their application in pharmaceutical and food applications.
\end{abstract}

\section{Introduction}

The microalgae Spirulina has been mainly used for human consumption and as feed or feed additives in poultry and aquaculture industry. Its nutritional and health benefits have lead to a great interest by healthcare and food industry for specific nutritional applications (Ghaeni \& Roomiani, 2016). Pre-clinical and clinical studies suggest that Spirulina has certain therapeutic effects such as: reduction in blood cholesterol, enhancement of the immune system, increasing of intestinal lactobacilli, reduction of nephrotoxicity by heavy metals and drugs, radiation protection, and reduction of hyperlipidemia and obesity (Ghaeni \& Roomiani, 2016; Sotiroudis \& Sotiroudis, 2013). Spirulina bioactivity is related to the compounds presented in their constitution such as phycocyanins, carotenoids, phenolic acids and omega3 and omega- 6 polyunsaturated fatty acids (Nuhu, 2013). Due to this,
Spirulina has a great potential to be exploited in a sustainable manner as a provider of bioactive compounds. These bioactive compounds can be extracted from microalgae using aqueous and alcoholic solutions, and present a great potential for inhibiting free radicals and thus acting as an antioxidant (Pyne, Bhattacharjee, \& Srivastav, 2017; Souza, Prietto, Souza, \& Furlong, 2015).

The use of natural antioxidants in food preservation, such as phenolic acids, has been presented as one of the ways to reduce the use of synthetic ones and in some cases can be used for the development of fortified foods. However, their susceptibility to hydrolytic and oxidative processes during food processing leads to changes in their antioxidant properties (Capanoglu, Beekwilder, Boyacioglu, De Vos, \& Hall, 2010). One of the strategies for the protection of phenolic compounds is their encapsulation in liposomes. Liposomes can preserve or even enhance their antioxidant activity, once they facilitate the permeation of

\footnotetext{
* Corresponding author at: INL - International Iberian Nanotechnology Laboratory, Av. Mestre José Veiga, Braga 4715-330, Portugal.

E-mail address: miguel.cerqueira@inl.int (M.A. Cerqueira).
} 
phenolic acids by the cell wall membrane, allowing a better performance in metabolic processes, as well as controlling their release and preventing their chemical degradation (Fang \& Bhandari, 2010). One of the major advantage of liposomes when compared to other carrier systems is their high biocompatibility, especially when consisting of naturally occurring lipids (Frezard, 1999).

The bioactive compounds incorporated in liposomes, can be protected against degradation, improving stability and solubility (e.g., solubilization of a hydrophobic compound in hydrophilic matrices and vice versa) (Machado et al., 2015). Several studies have shown that liposomes can be used to encapsulate vitamins (Zhou et al., 2014), antioxidants (Tan et al., 2014), proteins, peptides (Liu, Ye, Liu, Liu, \& Singh, 2013), minerals (Xia \& Xu, 2005) and fatty acids (Liu et al., 2011) as reported by Singh (2016). Their use for encapsulation of phenolic compounds extracted from microalgae has been performed before but to the best of authors' knowledge, the comparison between two lecithins (i.e. from rice and soybean) for this purpose has never been performed. Lipid materials have been widely used for encapsulation allowing the development of different delivery systems, such as emulsions, microemulsions, solid-lipid nanoparticles and nanoemulsions (Jeong, Park, \& Park, 2007; Silva, Cerqueira, \& Vicente, 2012). The main advantages of using lipid materials as encapsulating agents are the possibility of controlling the release of the bioactive compound, increased stability, and the possibility of large scale production (Mehnert \& Mäder, 2001). Lipid matrices with a high degree of disorder are a suitable alternative for the production of lipid particles, once less ordered crystal lattices can favor the inclusion of molecules during the encapsulation process and favor the control of the bioactive compounds' released (Attama \& Muller-Goymann, 2008; Muller, Radtke, \& Wissing, 2002; Severino, Pinho, Souto, \& Santana, 2011).

The use of in vitro gastrointestinal models allow the assessment of encapsulation systems behaviour during the digestion stages and has received great interest in the last years. In 2012, Liu et al. studied the physicochemical stability of crude liposomes and nanoliposomes formed from a membrane of the milk fat globule during in vitro digestion under conditions of the GI tract. Later on, lactoferrin encapsulated in liposomes prepared from phospholipid milk showed good stability, and liposomes showed that can prevent lactoferrin degradation and reduce the rate of hydrolysis under intestinal conditions (Liu et al., 2013). In another study, curcumin-loaded liposomes prepared by different methodologies were evaluated during in vitro digestion, and curcumin liposomes prepared by the pH-driven method showed similar bioaccessibility to those prepared by the thin film method and higher bioaccessibility than those prepared by the ethanol injection method (Cheng et al., 2017).

The aim of this study was the evaluation of soy and rice lecithin as encapsulating agents of phenolic compounds extracted from Spirulina LEB-18. They were used for the production of liposomes using reverse phase evaporation and characterized in terms of their size distribution, $\zeta$-potential and polydispersity index, being the chemical interactions evaluated through Fourier transform Infrared Spectroscopy (FTIR), and the crystallinity by X-ray diffraction (XRD) and differential scanning calorimetry (DSC). The release behavior of phenolic extracts was evaluated under two different $\mathrm{pH}$ conditions and an in vitro dynamic gastrointestinal model was used to simulate gastrointestinal conditions in stomach, duodenum, jejunum, and ileum, aiming to evaluate the behavior of liposomes containing the phenolic extract from Spirulina LEB-18 during the gastrointestinal tract.

\section{Material and methods}

\subsection{Materials}

Soybean lecithin (98.7\% purity) was purchased from Ativos Magistrais (Barueri, Brazil). Rice lecithin ( $92.4 \%$ purity) was provided by IRGOVEL industry of oil and fats (Pelotas, RS, Brazil). Ethyl acetate
(99.0\%) was purchased from Merck (Darmstadt, Germany), zinc sulfate, barium hydroxide, acetone, copper sulfate, potassium sodium tartrate, sodium carbonate, Folin-Ciocalteau, ethanol, methanol and phosphate buffer (PBS), pepsin from porcine gastric mucosa $\left(600 \mathrm{U} \mathrm{mL}^{-1}\right)$, lipase $\left(40 \mathrm{U} \mathrm{mL}^{-1}\right)$ and pancreatin from porcine pancreas $(8 \times \mathrm{USP})$, bile extract porcine, and the salts used for preparing the gastric and intestinal electrolytes, hydrochloric acid (37\%), and sodium bicarbonate were purchased from Sigma-Aldrich (St. Louis, MO, USA). The standards caffeic, chlorogenic, ferulic, gallic, hydroxybenzoic, protocatechuic acids and vanillin, were obtained from Sigma-Aldrich (St. Louis, MO, USA).

\subsection{Spirulina LEB-18}

Dried Spirulina LEB-18 biomass, lot 2014, was obtained as described by Morais and Costa (2008). The production was carried out in a pilot plant located on the shores of Lagoa Mangueira (Santa Vitória do Palmar, RS, Brazil). The unit consisted of three open tanks raceway type of $10,000 \mathrm{~L}$ capacity, and one open tank raceway type of $1000 \mathrm{~L}$ capacity to spread the inoculum. The cultures were protected in tunnel covered with UV transparent film and exposed to natural environmental conditions. When the microalgae concentration reached $0.50 \mathrm{~g} \mathrm{~L}^{-1}$, the biomass was separated by filtration, and dried in a tray dryer at $50{ }^{\circ} \mathrm{C}$ for $5 \mathrm{~h}$.

\subsection{Extraction of phenolic compounds}

The extraction of phenolic compounds was performed according to Souza, Recart, Rocha, Cipolatti, and Badiale-Furlong (2009), with some modifications. Briefly, $2 \mathrm{~g}$ of dried microalgae were mixed with $25 \mathrm{~mL}$ of methanol, followed by agitation in an orbital shaker TE-141 (TECNAL, Brazil), at $45^{\circ} \mathrm{C}$ for $120 \mathrm{~min}$ at $230 \mathrm{rpm}$. Then, the extract was centrifuged at $3220 \mathrm{~g}$ for $15 \mathrm{~min}$ and afterwards the solvents were evaporated in a rotary evaporator at $50{ }^{\circ} \mathrm{C}$. The extracts were filtered and clarified with $10 \mathrm{~mL}$ of $0.1 \mathrm{M}$ barium hydroxide and $10 \mathrm{~mL}$ of $5 \%$ zinc sulfate. The solutions were filtered and quantitatively transferred to a volumetric flask of $50 \mathrm{~mL}$, and the final volume was completed with water.

\subsubsection{Quantification of phenolic compounds}

The total phenolics content was analyzed in a UV-VIS spectrophotometer (Jasco V560, USA) at $760 \mathrm{~nm}$ (absorbance peak) using the Folin-Ciocalteu reagent, according to Souza et al. (2009) and Assis, Machado, Motta, Costa, and Souza-Soares (2014). Briefly, $500 \mu \mathrm{L}$ extract, $500 \mu \mathrm{L}$ of distilled water, and $4.5 \mathrm{~mL}$ of alkaline solution $(4 \%(w /$ v) carbonate sodium, $2 \%(\mathrm{w} / \mathrm{v})$ copper sulfate, and $2 \%(\mathrm{w} / \mathrm{v})$ potassium sodium tartrate) were used. After homogenization, the samples were subjected to heating at $40^{\circ} \mathrm{C}$ for $15 \mathrm{~min}$. Then, $500 \mu \mathrm{L}$ of $2 \mathrm{~N}$ FolinCiocalteau reagent diluted at 1:2 with distilled water was added. After $10 \mathrm{~min}$ of rest at room temperature, the absorbance was measured at $760 \mathrm{~nm}$. The total phenolics content was determined in the extracts by interpolating the absorbance of the samples to an analytical curve of gallic acid standard at concentrations ranging from 5 to $35 \mu \mathrm{g} \mathrm{m} L^{-1}$. Results were expressed as mg of gallic acid (GAE) per $g$ of microalgae. The coefficient of determination of the calibration curve was 0.9831 , being the equation $y=0.029 \times-0.030$.

\subsubsection{Identification of phenolic acids}

Aliquots of $20 \mathrm{uL}$ samples of phenolic extracts from Spirulina LEB-18 (diluted in water: methanol, 1:1) were injected into a chromatograph (Shimadzu, Tokyo, Japan, CLASS-M10A), flow $0.9 \mathrm{~mL} \mathrm{~min}^{-1} 103 \mathrm{Kgf} /$ $\mathrm{cm}^{2}$ at a temperature of $35^{\circ} \mathrm{C}$. The separation of the phenolic acids was accomplished using a C18 reverse phase column $(4.6 \times 250 \mathrm{~mm}, 5 \mu \mathrm{m}$; Bondesil, Agilent Technologies, CA, EUA) and an isocratic gradient of solvents consisting of methanol and acidified water (acetic acid 1\%) in the ratio $20: 80 \mathrm{v} / \mathrm{v}$ for $25 \mathrm{~min}$, using detection at $280 \mathrm{~nm}$ to $320 \mathrm{~nm}$ and 
$15 \mathrm{~min}$ to $25 \mathrm{~min}$. Phenolic acids were identified by comparison of retention times and absorption spectra with various standards such as caffeic, chlorogenic, ferulic, gallic, hydroxybenzoic, protocatechuic and vanillin as described in the literature (Pourali, Asghari, \& Yoshida, 2010; Mira, Barros, Schiocchet, Noldin, \& Lanfer-Marquez, 2008;. Zhou et al., 2004). The limit of detection (LOD) was determined by the ratio of white noise signal (solution containing the solvent used in the extraction of phenolic compounds) of 3:1. The limit of quantification (LOQ) was established as being three times the LOD (Ribani, Bottoli, Collins, Jardim, \& Melo, 2004). The method was used according to Schmidt, Gonçalves, Prietto, Hackbart, and Furlong (2014) with modifications.

\subsection{Purification of rice lecithin and soybean lecithin}

Purification of rice and soybean lecithins was performed according to Mertins, Sebben, Schneider, Pohlmann, and Silveira (2008) and Machado et al. (2014). First, $50 \mathrm{~g}$ of sample were dissolved in $250 \mathrm{~mL}$ of ethyl acetate. Then, $10 \mathrm{~mL}$ of distilled water were added at slow stirring, thus leading to the formation of two phases. The supernatant was separated and the lower phase discarded. The gel-like phase was dispersed in $150 \mathrm{~mL}$ of acetone, forming agglomerates that were broken up using a glass rod. Then, the acetone was decanted, and a new portion of $250 \mathrm{~mL}$ was added, repeating the extraction step. The precipitate was filtered under vacuum, and dried in an oven at $60{ }^{\circ} \mathrm{C}$, and cooled in a desiccator, thus obtaining $32 \mathrm{~g}$ and $36 \mathrm{~g}$ of purified phosphatidylcholine from rice lecithin (RL) and soybean lecithin (SL), respectively.

\subsection{Production of liposomes by reverse phase evaporation}

Liposomes were produced by reverse phase evaporation, according to Szoka and Papahadjopoulos (1978), with some modifications. For the production process, $1 \mathrm{~g}$ of purified phospholipid from RL and SL was weighed separately in a round bottom flask and homogenized with $20 \mathrm{~mL}$ of ethanol in an ultrasonic bath. Then, ultra pure water $(20 \mathrm{~mL})$ was added to the RL and SL samples, while $0.2 \mathrm{~g}$ of total phenolic extracts from Spirulina LEB-18 dissolved in $20 \mathrm{~mL}$ of ultra-pure water was added to RL and SL samples. The mixtures were stirred for $1 \mathrm{~min}$ to complete dispersion, and then ethanol was evaporated in a rotary evaporator until the formation of a lipid film on the wall of the flask. Then, the samples were heated at $60^{\circ} \mathrm{C}$ in a water bath for $40 \mathrm{~min}$, followed by vortex mixing (RSLAB-6PRO, Auxilab SL, Spain) and sonication (5510 Branson, Danbury, CT, USA) during 6 min each, until a total of 10 cycles, to reduce the size and homogenize liposomes.

Subsequently, the liposomes obtained were stored in amber bottles and placed in a refrigerator at $4{ }^{\circ} \mathrm{C}$. Liposomes from rice lecithin and soybean lecithin were named RL and SL, respectively, and with the encapsulation of phenolic extracts are called S-RL and S-SL, respectively.

\subsection{Caracterization of lipossomes}

\subsubsection{Size distribution and polydispersity index}

Liposomes without and with phenolic extracts were characterized in terms of size distribution (by number) and polydispersity index (PdI) using a Dynamic Light Scattering (DLS) apparatus (Zetasizer Nano ZS, Malvern Instruments, UK) equipped with a $\mathrm{He}-\mathrm{Ne}$ laser at a wavelength of $633 \mathrm{~nm}$. All measurements were performed at $25^{\circ} \mathrm{C}$. Each measurement of size and PDI was performed with a detection angle of $173^{\circ}$. The results are given as the average \pm standard deviation of nine measurements.

\subsection{2. $\zeta$-Potential}

$\zeta$-potential measurement was carried out at room temperature $\left(25^{\circ} \mathrm{C}\right)$ using a Zetasizer Nano ZS (Malvern Instruments, UK) in a folded capillary cell using a He-Ne laser-wavelength of $633 \mathrm{~nm}$ and a detector angle of $173^{\circ}$. The measurements were made in triplicate, with three readings for each sample. The results are given as the average \pm standard deviation of nine measurements.

\subsubsection{Encapsulation efficiency}

Encapsulation efficiency (EE) was determined through the separation of the loaded particles from free phenolic extract. The separation was carried out using Amicon Ultra-0.5 (Amicon Ultra- $0.5 \mathrm{~mL} 3 \mathrm{~K}$ device, Millipore Corp., Ireland), followed by centrifugation at $14000 \mathrm{~g}$ for $30 \mathrm{~min}$. EE was detemined according to Eq. (1):

$E E(\%)=\left(\frac{[t p c-f p c]}{t p c}\right) \times 100$

where tpc corresponds to the total phenolic compounds and $f p c$ corresponds to the free phenolic compounds.

\subsubsection{Loading capacity}

Loading capacity (LC) was determined by quantifying the weight of liposomes (after drying) (Luo, Teng, \& Wang, 2012; Luo, Zhang, Whent, Yu, \& Wang, 2011). LC was determined according to Eq. (2):

$L C(\%)=\left(\frac{[t p c-f p c]}{w l}\right) \times 100$

where $t p c$ corresponds to the total phenolic compounds, $f p c$ corresponds to free phenolic compounds and $w l$ the weight of liposome.

\subsubsection{Fourier transform infrared spectroscopy (FTIR)}

To determine the functional groups of liposomes, FTIR analysis were carried out in Attenuated Total Reflectance mode (ATR) between 500 and $4000 \mathrm{~cm}^{-1}$, using 16 scans at a resolution of $4 \mathrm{~cm}^{-1}$ (Perkin-Elmer 16 PC spectrometer, Boston, USA). Before analysis, an open bean background spectrum of clean crystal was recorded. The samples were freeze-dried before analysis (Freeze dryer Christ Alpha 1-4 LD, Martin Christ, Germany).

\subsubsection{Transmission electron microscopy (TEM)}

TEM micrographs were conducted on a Zeiss EM 902A microscope (Germany) at an accelerating voltage of $50 \mathrm{kV}$ and $80 \mathrm{kV}$. The samples were prepared by dropping liposomes solutions onto copper grids coated with carbon film, followed by staining with uranyl acetate and natural drying at room temperature (Bourbon et al., 2015).

\subsubsection{Differential scanning calorimetry (DSC)}

DSC measurements were performed in a PerkinElmer DSC 6000 equipment (Perkin Elmer, USA). About $10 \mathrm{mg}$ of sample were placed in aluminium DSC pans and heated from 20 to $250{ }^{\circ} \mathrm{C}$ at a heating rate of $30^{\circ} \mathrm{C} \mathrm{min}^{-1}$ under nitrogen atmosphere. Two replicates were performed for each sample. The samples were freeze-dried before analysis (Freeze dryer Christ Alpha 1-4 LD, Martin Christ, Germany).

\subsection{8. $X$-ray diffraction $(X R D)$}

$\mathrm{X}$-ray diffraction patterns of the liposomes were analyzed between $2 \theta=4$ and $2 \theta=60^{\circ}$ with a step size $2 \theta=0.02^{\circ}$ in an X-ray diffraction instrument (Bruker D8 Discover, USA). The samples were freeze-dried before analysis (Freeze dryer Christ Alpha 1-4 LD, Martin Christ, Germany).

\subsection{In vitro release}

The in vitro release of the phenolic extracts was performed by the dialysis method at $37{ }^{\circ} \mathrm{C}$. Loaded liposomes $(5 \mathrm{~mL})$ were added into a dialysis membrane (cut-off $10 \mathrm{kDa}$; Orange Scientific H1), which was placed into $40 \mathrm{~mL}$ buffer (phosphate buffer $\mathrm{pH}=7$ or KCl-HCl buffer $\mathrm{pH}=2$ ) under magnetic stirring. At appropriate intervals, $0.5 \mathrm{~mL}$ of supernatant was sampled and $0.5 \mathrm{~mL}$ of fresh buffer was added to keep 
the volume constant. The amount of phenolic extract released from the liposomes was determined at $760 \mathrm{~nm}$ (absorbance peak) (Elisa Biotech Synergy HT, Biotek, USA). All trials were performed at least in triplicate.

To evaluate the liposome release mechanisms, a kinetic model, which accounts for both Fickian and Case II transport effects in hydrophilic matrices was applied (linear superposition model, LSM) (Eq. (3)) (Berens \& Hopfenberg, 1978).

$M_{t}=M_{t, F}+M_{t, R}$

where $M_{t, F}$ and $M_{t, R}$ are the contributions of the Fikian and relaxation processes, respectively, at time $t$ (Jeong, Bae, \& Kim, 1999). The Fickian process is described as:

$M_{t}, F=M^{\infty}, F\left[1-\frac{6}{\pi^{2}}\right] \sum_{n=1}^{\infty} \frac{1}{n^{2}} \exp \left(-n^{2} K_{F} t\right)$

where $M_{\infty, F}$ is the compound released at equilibrium, and $K_{F}$ is the Fickian diffusion rate constant. Eq. (4) can be simplified using first term of the Taylor series (Pinheiro et al., 2012; Pinheiro et al., 2015).

As for liposome relaxation, it is driven by the swelling ability of the liposome and is then related to the dissipation of stress induced by the entry of the penetrant and can be described as a distribution of relaxation times, each assuming a first order-type kinetic equation (Berens \& Hopfenberg, 1978).

$M_{t, R}=\sum_{i} M^{\infty}, R i[1-\exp (-K R i, t)]$

where $M_{\infty}$, and $R_{i}$ are the contributions of the relaxation process for compound release; $K_{R \mathrm{i}}$ are the relaxation rate constant. For most cases, there is only one main relaxation that affects the transport, thus the equation above can be simplified using $i=1$, as follows:

$\frac{M_{t}}{M^{\infty}}=x\left[1-\frac{6}{\pi^{2}} \exp \left(k_{F} t\right)\right]+(1-x)\left[1-\exp \left(-k_{R} t\right)\right]$

where $X$ is the fraction of the compound released by Fickian transport.

The experimental results were analyzed by adjusting the Eq. (3) (Fick's Law) and Eq. (6) (linear superposition model) to assess the transport mechanism involved in the release of phenolics from the liposome particles at two different $\mathrm{pH}$ values ( 2 and 7 ).

\subsection{In vitro digestion}

\subsubsection{Gastrointestinal model}

A dynamic gastrointestinal system was used for in vitro digestion experiments (Mantovani, Pinheiro, Vicente, \& Cunha, 2017). This model simulates the major events that occur during digestion, and consists of four compartments simulating the stomach, duodenum, jejunum, and ileum. Each compartment consists of two glass reactors connected with a flexible wall, and water is pumped around the flexible walls to maintain the temperature at $37^{\circ} \mathrm{C}$ and to allow the simulation of peristalsis (by alternate compression and relaxation of the flexible walls). Changes in water pressure are achieved by peristaltic pumps, which alter the flow direction as a function of time.

The compartments are connected by silicone tubing, and a constant volume of chyme is transferred at a preset time. All compartments are equipped with $\mathrm{pH}$ electrode, and $\mathrm{pH}$ is controlled by the secretion of $\mathrm{HCl}\left(1 \mathrm{~mol} \mathrm{~L}^{-1}\right)$ and $\mathrm{NaHCO}_{3}\left(1 \mathrm{~mol} \mathrm{~L}^{-1}\right)$ into the stomach and intestinal compartments, respectively. The gastric and intestinal juices are added using syringe pumps at preset flow rates. The jejunum and ileum compartments are connected with hollow-fiber devices (SpectrumLabs Minikros ${ }^{\circledR}, \mathrm{M} 20 \mathrm{~S}-100-01 \mathrm{P}, \mathrm{USA}$ ), to absorb water and products from chyme, and to modify the concentration of electrolyte and bile salts from chyme (Pinheiro, Coimbra, \& Vicente, 2016; Reis et al., 2008).

\subsubsection{Experimental conditions}

In vitro dynamic digestion was performed by simulating the gastric, duodenal, jejunal, and ileal portions of the GI tract, as described by other authors (Reis et al., 2008) with modifications (Pinheiro et al., 2016). The gastric secretion consisted of pepsin and lipase in gastric electrolyte solution $\left(4.8 \mathrm{~g} \mathrm{~L}^{-1} \mathrm{NaCl} ; 2.2 \mathrm{~g} \mathrm{~L}^{-1} \mathrm{KCl} ; 0.22 \mathrm{~g} \mathrm{~L}^{-1} \mathrm{CaCl}_{2}\right.$; and $1.5 \mathrm{~g} \mathrm{~L}^{-1} \mathrm{NaHCO}_{3}$ ) at a flow rate of $0.5 \mathrm{~mL} \mathrm{~min}^{-1}$. The $\mathrm{pH}$ in the stomach was controlled to follow a predetermined curve (from 4.8 at $t=0$ to 1.7 at $t=120 \mathrm{~min})$ by secreting $\mathrm{HCl}\left(1 \mathrm{~mol} \mathrm{~L}^{-1}\right)$. The duodenal secretion consisted of a mixture of $30 \mathrm{~mL}$ of $4 \%(w / v)$ porcine bile extract, $15 \mathrm{~mL}$ of $7 \%(\mathrm{w} / \mathrm{v})$ pancreatin solution, and $9 \mathrm{~mL}$ of small intestine electrolyte solution (SIES) $\left(5 \mathrm{~g}^{-1} \mathrm{NaCl} ; 0.6 \mathrm{~g} \mathrm{~L}^{-1} \mathrm{KCl} ; 0.25 \mathrm{gL}^{-1}\right.$ $\mathrm{CaCl}_{2}$ ) at a flow rate of $0.9 \mathrm{~mL} \mathrm{~min}^{-1}$. The jejunal fluid secretion consisted of SIES containing $10 \%(\mathrm{v} / \mathrm{v})$ porcine bile extract at a flow rate of $3.2 \mathrm{~mL} \mathrm{~min}^{-1}$. The ileal secretion fluid consisted of SIES at a flow rate of $3.0 \mathrm{~mL} \mathrm{~min}^{-1}$. The $\mathrm{pH}$ in the different parts of small intestine was controlled by the addition of $1 \mathrm{~mol} \mathrm{~L}^{-1} \mathrm{NaHCO}_{3}$ to reach $\mathrm{pH} 6.5,6.8$, and 7.2 for the simulated conditons in duodenum, jejunum, and ileum, respectively (Pinheiro et al., 2013).

The in vitro digestions were performed to evaluate the bioaccessibility of the the phenolic extracts encapsulated in liposomes. In addition, the samples from different in vitro digestion stages were characterized for size distribution, $\zeta$-potential, morphology (TEM) and free fatty acids (FFA) release.

\subsubsection{Free fatty acids}

Free fatty acids content was determined by titration with $0.1 \mathrm{M}$ $\mathrm{NaOH}$ (Pinheiro et al., 2013), and a blank was used to determine the fatty acids released, as shown in the following Eq. (7) (Pinsirodom, 2005):

$F F A(\%)=\left(\frac{V_{\mathrm{NaOH}} \times m_{\mathrm{NaOH}} \times M_{\text {lipid }}}{W_{\text {lipid }} \times 2}\right) \times 100$

where $V_{\mathrm{NaOH}}$ is the volume of sodium hydroxide required to neutralize the FFA generated (in $\mathrm{mL}$ ), $m_{\mathrm{NaOH}}$ is the molarity of the sodium hydroxide used (in mol L ${ }^{-1}$ ), $W_{\text {Lipid }}$ is the weight of soybean/rice oil initially present and $M_{\text {Lipid }}$ is the molecular weight of the soybean/rice oil (based on their average fatty acid composition the molecular weight of soybean/rice oil was considered to be $775 \mathrm{~g} \mathrm{~mol}^{-1}$ ).

\subsubsection{Bioaccessibility of phenolic extracts}

A sample was collected at the end of the simulated intestinal system and the bioaccessibility of phenolic extracts performed through the quantification of total phenols through the equation:

Bioaccessibility $(\%)=\left(\frac{\sum(S J+S I)}{T}\right) \times 100$

where $S J$ is the phenolic extract in the jejunum filtrate sample, $S I$ is the phenolic extract in the ileum filtrate sample and $T$ is the total of free phenolic extract.

\subsection{Statistical analysis}

Data were analyzed by Analysis of variance (ANOVA), followed by Tukey's test at a significance level of $\mathrm{p}<0.05$.

Models were fitted to in vitro release data by non-linear regression, using a package of STATISTICA ${ }^{\mathrm{TM}}$ v7.0 (Statsoft. Inc., USA). The Levenberg-Marquardt algorithm for the least squares function minimization was used. The quality of the regressions was evaluated on the basis of the determination coefficient, $R^{2}$, the squared root mean square error, RMSE (i.e., the square root of the sum of the squared residues (SSE) divided by the regression degrees of freedom) and residuals visual inspection for randomness and normality. $R^{2}$ and SSE were obtained directly from the software. The precision of the estimated parameters was evaluated by the standardised halved widt (SHW \%), which was 


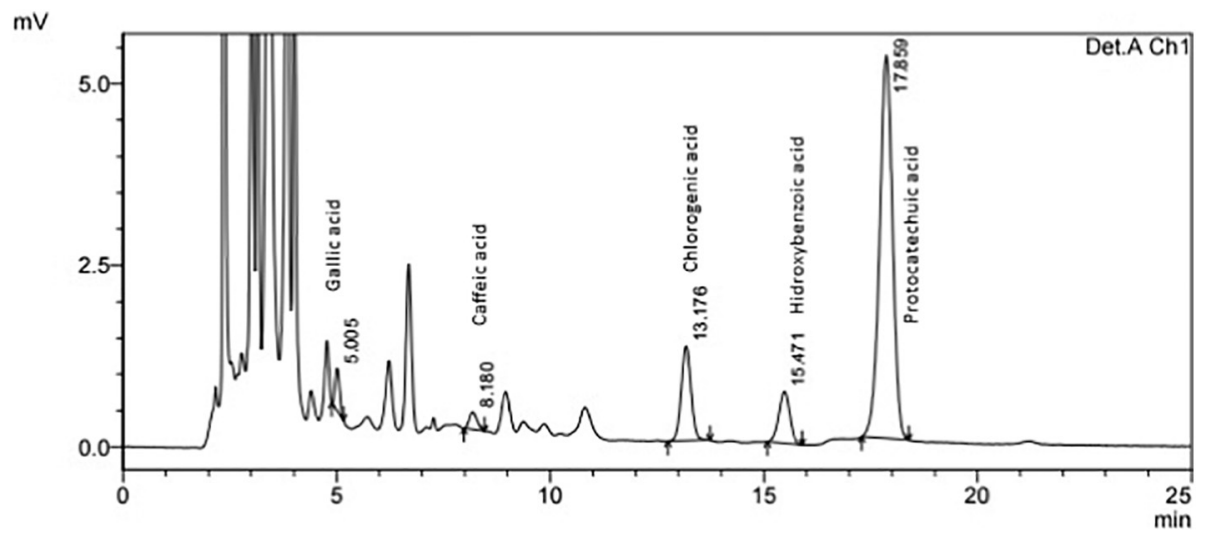

Fig. 1. Chromatogram of the Spirulina LEB-18 extract with the identification of the phenolic acids.

defined as the ratio between the $95 \%$ standard error (obtained from the software) and the value of the estimate.

\section{Results and discussion}

\subsection{Identification and quantification phenolics}

Phenolics presented in the Spirulina LEB-18 extracts, were identified and quantified using HPLC coupled to a UV detector. Fig. 1 shows the chromatogram of the phenolic acids identified. The phenolic acids identified include gallic acid (17.74 $\left.\mu g_{\text {compound }} / g_{\text {extract }}\right)$, caffeic acid (47.02 $\mu \mathrm{g}_{\text {compound }} / \mathrm{g}_{\text {extract }}$ ), chlorogenic acid (19.27 $\mu \mathrm{g}_{\text {compound }} / \mathrm{g}_{\text {extract }}$ ), protocatechuic ( $11.06 \mu \mathrm{g}_{\text {compound }} / \mathrm{g}_{\text {extract }}$ ), hydroxybenzoic acid (54.66 $\mu \mathrm{g}_{\text {compound }} / \mathrm{g}_{\text {extract }}$ ). These results are in agreement with other studies for other species of microalgae. According to Colla, Badiale-Furlong, and Costa (2007) and Parisi, Younes, Reinehr, and Colla (2009) the phenolic compounds presented in Spirulina LEB-18 are gallic acid, caffeic acid, salicylic acid, trans-cinnamic acid, chlorogenic acid and synaptic acid. In this study five phenolic acids were found, but only three are similar to the results presented by Colla et al. (2007), Parisi et al., (2009) and Machado, Graça, Assis, and Souza-Soares (2017). These differences may be related with the differences in cultivation and analytical methodology used for extraction (Machado et al., 2017).

\subsection{Liposomes characterization}

\subsubsection{Size distribution, polydispersity index and $\zeta$-potential}

Table 1 presents the size distribution, polydispersity index, and $\zeta$ potential of the liposomes produced with RL and SL whithout and with the encapsulation of phenolic extracts obtained from Spirulina LEB-18 (S-RL and S-SL, respectively). Results show that liposomes obtained from RL present higher $(p<.05)$ size distribution values than the ones obtained for SL. Moreover, the incorporation of the phenolic extracts in liposomes (S-RL, S-SL) led to an increase $(p<.05)$ of the size distribution for both types of liposomes. This increase can be explained by the presence of encapsulated phenolic extracts in the liposomes structure. During the formation of the liposomes, by reverse phase evaporation, the phenolics are incorporated in the aqueous phase of liposomes leading to an increase of the size distribution. The morphology of the liposomes was also analyzed by transmission electron microscopy (TEM), which showed vesicles of spherical shape in all images (Fig. 2). In addition, the size distribution was heterogeneous being clear the presence of some aggregates, which is in agreement with the PDI values obtained (Table 1). The results are in agreement with other works, where have been reported a size distribution above $200 \mathrm{~nm}$ for liposomes used in the encapsulation of phenolic extracts (Assis et al., 2014; Priprem, Watanatorn, Sutthiparinyanont, PhaChonpai, \& Muchimapura, 2008; Takahashi, Uechi, Takara, Asikin, \& Wada, 2009).

Liposomes present $\zeta$-potential values of $-18.40 \pm 1.13$ and $-46.73 \pm 0.85 \mathrm{mV}$ for rice and soybean lechitins liposomes, respectively. The negative $\zeta$-potential values may be explained by the presence of the phosphatidic acid in the phosphatidylcholine from rice and soybean used in the production of liposomes. The values are in agreement with other work, with formation of negatively charged particles due to the presence of lecithin (Assis et al., 2014). $\zeta$-potential can be changed according to the composition of phospholipid of each lecithin. In this study, phosphatidylcholine (PC) was used, which is considered a zwitterionic phospholipid or zero load, with a positive group (choline) and a negative group (phosphate) (Kramer, JakitsDeiser, \& Wunderli-Allenspach, 1997; Kramer \& Wunderli-Allenspach, 1996). Another important factor is the difference between RL and SL with respect to fatty acids type, being predominantly oleic acid in RL and linoleic acid in SL (Machado, Assis, et al., 2014), which can explaind the differences obtained for the values of $\zeta$-potential.

In both cases, the samples containing the phenolic extracts of Spirulina LEB-18 present $\zeta$-potential values $(-11.63 \pm 0.23$ for S-RL and $-11.00 \pm 0.40 \mathrm{mV}$ for S-SL) lower (closer to zero) than the liposomes without bioactive compounds $(-18.40 \pm 1.13 \mathrm{mV}$ for $\mathrm{RL}$ and $-46.73 \pm 0.85 \mathrm{mV}$ for SL). This decrease may be due to the encapsulation of the phenolic extracts in liposomes, once the phenolic extracts presented $\zeta$-potential values close to $-0.8 \mathrm{mV}$ and therefore

Table 1

Size distribution (SD), polydispersity index (PDI) and $\zeta$-potential of liposome without and with phenolic extracts, and encapsulation efficiency and loading capacity of liposomes containing phenolic extracts.

\begin{tabular}{llllll}
\hline Sample & SD $(\mathrm{nm})$ & PDI & $\zeta$-potential $(\mathrm{mV})$ & Encapsulation efficiency (\%) & Loading capacity (\%) \\
\hline RL & $263.6 \pm 1.5^{\mathrm{c}}$ & $0.460 \pm 0.007^{\mathrm{b}}$ & $-18.40 \pm 1.13^{\mathrm{b}}$ & - & \\
S-RL & $291.9 \pm 1.8^{\mathrm{a}}$ & $0.524 \pm 0.006^{\mathrm{a}}$ & $-11.63 \pm 0.23^{\mathrm{c}}$ & $97.35 \pm 0.57^{\mathrm{a}}$ & - \\
SL & $250.5 \pm 38^{\mathrm{d}}$ & $0.400 \pm 0.028^{\mathrm{c}}$ & $-46.73 \pm 0.85^{\mathrm{a}}$ & - & \\
S-SL & $269.4 \pm 0.2^{\mathrm{b}}$ & $0.383 \pm 0.004^{\mathrm{c}}$ & $-11.00 \pm 0.40^{\mathrm{c}}$ & $88.28 \pm 0.74^{\mathrm{b}}$ & - \\
\hline
\end{tabular}

Liposome from rice lecithin - RL; Liposome from soybean lecithin - SL; Liposome from rice lecithin with phenolic extratcs - S-RL; Liposome from soybean lecithin with phenolic extracts - S-SL;

Means in the same column with the different superscripts $(a, b, c)$ are statistically differrent $(p<0.05)$. 


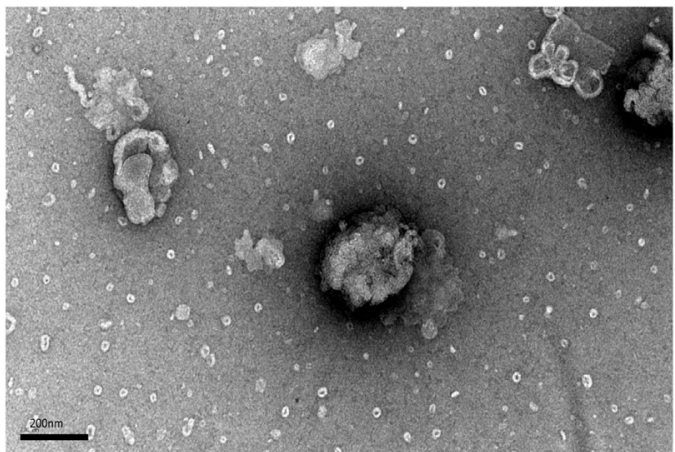

a)

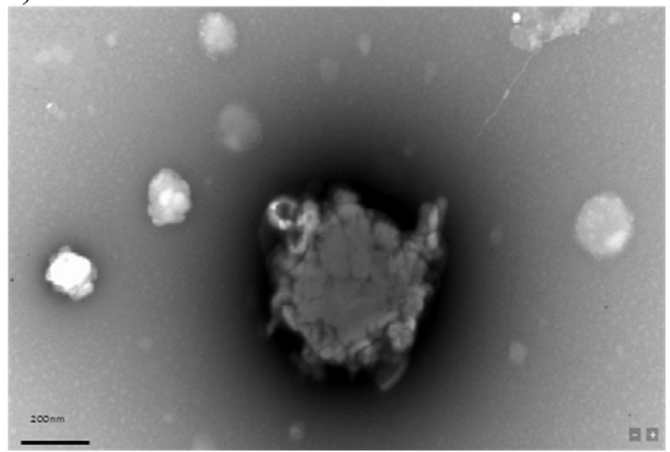

c)

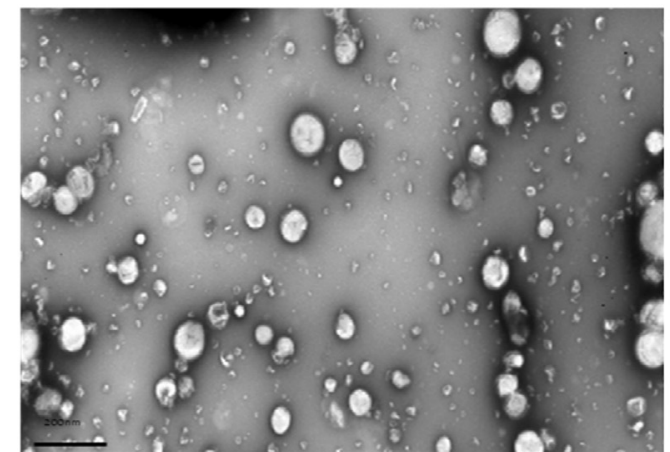

b)

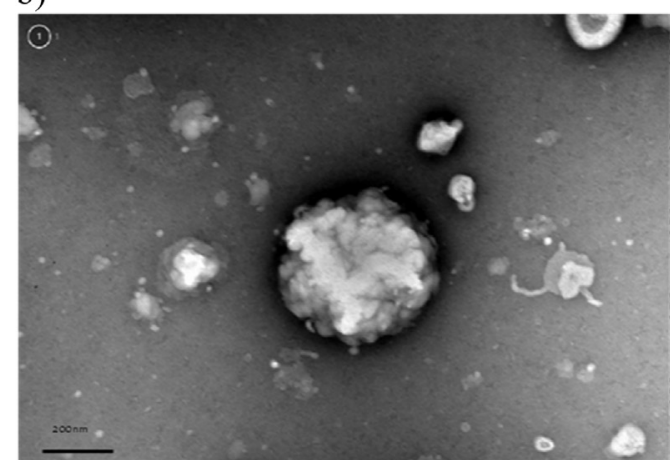

d)

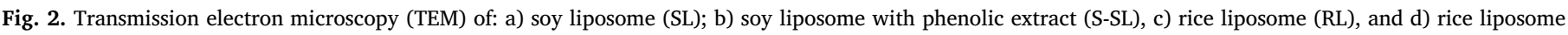
with phenolic extract (S-RL). Scale bar of $200 \mathrm{~nm}$.

influence the overall value of $\zeta$-potential. The magnitude of the $\zeta$-potential can be related with physical stability of a colloidal system, once if all particles of a suspension present a high $\zeta$-potential (negative or positive), they will repel each other and thus decrease the tendency to the formation of aggregates. It was reported that particles with a $\zeta$ potential higher than $30 \mathrm{mV}$ (absolute value) are considered to be physically stable, as is the case of SL, while $\zeta$-potential near $20 \mathrm{mV}$ (positive or negative) suggests low stability of the colloidal suspension, and for values in the range of $-5 \mathrm{mV}$ to $+5 \mathrm{mV}$ can be observed a rapid aggregation of particles (Mishra, Ram, \& Ghosh, 2009).

\subsubsection{Encapsulation efficiency and loading capacity}

The developed liposomes showed high EE and LC values (Table 1) for both type of liposomes (rice and soybean). However, the values for liposomes produced using rice lecithin are higher for both EE and LC, probably due to rice lecithin composition. Rice lecithin contains higher levels of phospholipids when compared to soybean (Orlandelli, 2008), which can explain these differences. Morais et al. (2003) studied reverse phase evaporation method for preparing liposomes of casein hydrolysates, and obtained EE values ranging between $56 \%$ and $62 \%$, according to the determination method. They showed that the EE determined by an indirect method of consecutive centrifugation present lower values than the one determined using filtration with Amicon, although the same encapsulation technique was used. Assis et al. (2014) studied the encapsulation of methanolic extract of Spirulina in soybean lecithin-based liposomes, and found an EE value of $87.85 \%$, which was lower than the values observed for S-RL $(97.35 \pm 0.57 \%)$ and similar to the values found for S-SL $(88.28 \pm 0.74 \%)$. Machado, Assis, et al. (2014) studied liposomes subjected to homogenization and obtained higher EE values (90\%) when compared with liposomes subjected to ultrasound (79\%). Menon, Teo, and Misran (2015) found an EE of $96.7 \%$ for curcumin encapsulated in coated liposomes $(0.025 \%, w / v)$, and values of $93.7 \%$ in uncoated liposomes. Based on this, it can be stated that both SL and RL present good values of EE. Neverthless, results for LC were lower than the one obtained by Pamunuwa, Bandara,
Karunaratne, and Karunaratne (2015) that reached values of $8 \%$ for liposomes encapsulating plant extracts. In other study, curcumin-loaded liposomes showed values near to the ones observed in this work, with LC values of 3.4\% (Pamunuwa, Karunaratne, \& Karunaratne, 2016).

\subsubsection{Fourier transform infrared spectroscopy (FTIR)}

FTIR was used to identify the functional groups of the developed liposomes as well as to evaluate possible changes in the liposomes' structure after the incorporation of phenolic extracts. Fig. 3 presents the FTIR spectra of the produced liposomes RL, SL, S-RL, and S-SL. The phenolic acids are composed by a benzene ring, and one or more groups of hydroxyl and/or methoxyl. The frequency of the bands defines the presence ou absence of hidrogen bonds between phosphate groups and hydrogen atoms, water molecules, or biological macromolecules (KanZhi et al., 1996). The FTIR spectra indicates an interaction between the phenolic compounds containing $\mathrm{C}=\mathrm{O}$ and $\mathrm{PO}_{2}$ groups from

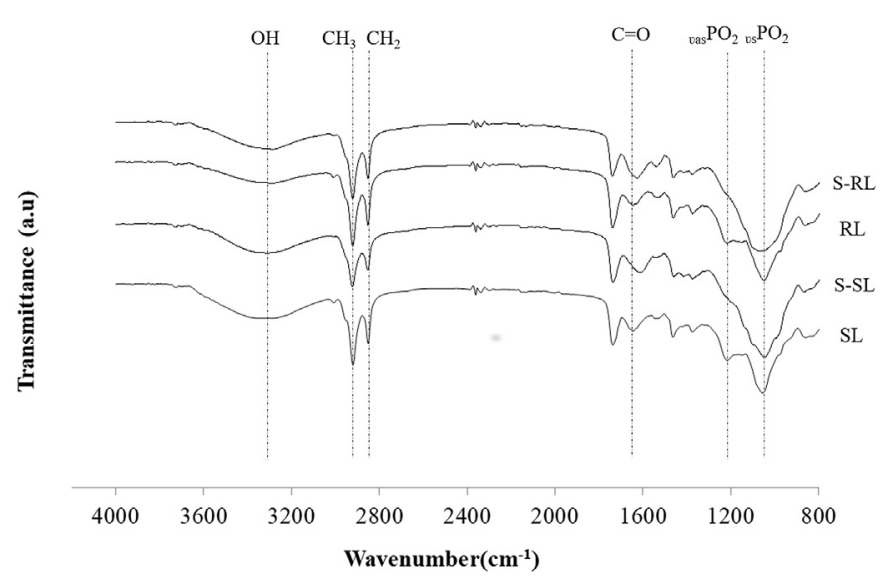

Fig. 3. FTIR spectra of soy liposome (SL), soy liposome with phenolic extracts (S-SL), rice liposome (RL), and rice liposome with phenolic extracts (S-RL). 
phosphatidylcholine. The incorporation of phenolic extracts in liposomes lead to a change on $\mathrm{PO}_{2}$ strechning vibration, in both assymetric (around $1200 \mathrm{~cm}^{-1}$ ) and symetric vibration (arounf $1035 \mathrm{~cm}^{-1}$ ) (Cagnasso, Boero, Franchini, \& Chorover, 2017). The influence of phenolic acids on the peaks of the phosphate group of lecithins, suggests a preferable location in the polar region of the lipids. The phenolic compounds located in the polar part of the membrane can impair the interaction between lipid molecules, increasing permeability and fluidity (Toyran \& Severcan, 2003). With respect to $\mathrm{C}=\mathrm{O}$, a shift of the stretching vibration for liposomes with phenolic extracts was also observed in this study. The encapsulation of phenolic extracts in liposomes presented small variations between stretching of these groups, being in agreement with the results obtained by Zavareze et al. (2014). A difference in stretching vibration was observed for the choline group, which is present in the polar part of phosphatidylcholine. Those authors also observed a stretching vibration at $2852 \mathrm{~cm}^{-1}$ and $2850 \mathrm{~cm}^{-1}$, representing the $\mathrm{CH}_{2}$. The $\mathrm{CH}_{2}$ stretching that reflects the inner part of the lipid bilayer of liposome, does not present significant differences, which is in agreement with the expected effect of the phenolics in the apolar part of the liposome structure (Bai et al., 2011).

\subsubsection{Differential scanning calorimetry (DSC)}

DSC was used to understand the effect of the phenolic extracts in thermal behavior of the crystalline phase of the liposomes from rice and soybean lecithin. For that, phase transition temperatures (onset, peak and endset) and enthalpy energy were determined (Table 2). All samples showed a positive enthalpy variation, indicating endothermic peaks, which is related to the absorbed energy along heating by liposome molecules (Yokota, Moraes, \& Pinho, 2012). The enthalpy variation $(\Delta H)$ reflects the van der Waals interactions between the lipid acyl chains and those modified by the interaction with the phenolics. These parameters are related to lipid order (De Lima et al., 2010; ManriqueMoreno, Howe, Suwalsky, Garidel, \& Brandenburg, 2010). This behaviour is related to the non-covalent associations of processes, including conformational changes in the acyl chains pack form. Phospholipids are also characterized by a phase transition temperature $\left(60^{\circ} \mathrm{C}\right)$, in which a lipid membrane goes from a gel phase, where the hydrocarbon chain of the lipid is an ordered phase, to a liquid-crystalline phase, where the tails are left with freer motions and the hydrophilic heads grouped become completely hydrated (Machado, 2016). Chanda, Das, Chakraborty, and Ghosh (2011) also showed this behavior in the development of liposomes for encapsulation of fluconazole, reporting an endothermic event for the fluconazole-loaded liposome.

The results showed that the phenolic extracts changed the behavior of the lipid bilayer and the organization of the membrane, with an increase in enthalpy energy variation (Table 2). This behavior can be explained by the fluidifying effect of the phenolic acids of Spirulina sp. in the hydrophobic region of liposomes (phosphatidylcholine). These results are in agreement with results obtained for extract of rosemary (Rosmarinus officinalis), quercetin, naringenin, and hesperidin (Gutiérrez et al., 2003; Saija et al., 1995). Saija et al. (1995) and Pagnussatt et al. (2016), confirmed the interaction observed between flavonoids and phenolic extracts with liposomes, and the consequently

Table 2

Onset temperature $\left(T_{o}\right)$, peak temperature $\left(T_{p}\right)$, endset temperature $\left(T_{e}\right)$ and enthalpy energy variation $(\Delta H)$ obtained by DSC for liposomes.

\begin{tabular}{lllll}
\hline Sample & $T_{o}\left({ }^{\circ} \mathrm{C}\right)$ & $T_{p}\left({ }^{\circ} \mathrm{C}\right)$ & $T_{e}\left({ }^{\circ} \mathrm{C}\right)$ & $\Delta H(\mathrm{~J} / \mathrm{g})$ \\
\hline $\mathrm{RL}$ & 121.00 & 136.04 & 157.67 & 74.52 \\
S-RL & 122.09 & 141.16 & 167.36 & 145.17 \\
SL & 126.35 & 154.58 & 203.54 & 75.14 \\
S-SL & 127.47 & 144.44 & 180.69 & 121.06 \\
\hline
\end{tabular}

Liposome from rice lecithin - RL; Liposome from soybean lecithin - SL; Liposome from rice lecithin with phenolic extracts - S-RL; Liposome from soybean lecithin with phenolic extracts - S-SL.

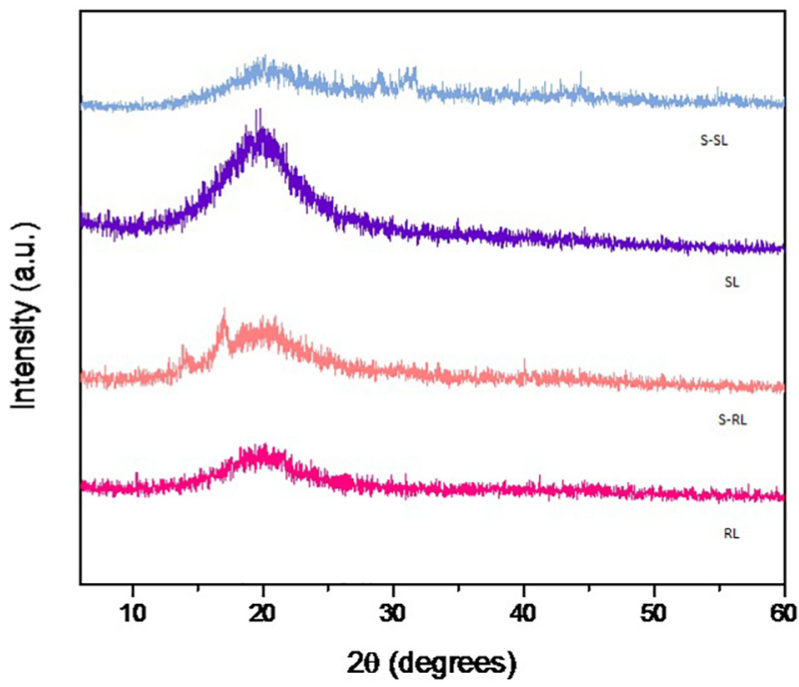

Fig. 4. X-ray diffraction of soy liposome (SL), soy liposome with phenolic extracts (S-SL), rice liposome (RL), and rice liposome with phenolic extract (S-RL).

fluidifying effect due to migration of lipophilic molecules in the ordered structure of the lipid bilayer.

\subsubsection{X-ray diffraction}

$\mathrm{X}$-ray diffraction is used to evaluate the crystalline-amorphous state of materials (Di Cola, Grillo, \& Ristori, 2016). In general, the crystalline material shows a series of sharp peaks, while amorphous materials produce broad and non-defined peaks (Caparino et al., 2012).

Fig. 4 shows a very broad peak, indicating that the bilayer liposomes without rice and soybean phenolic extracts shows no structure, which is typical of amorphous materials. Rice and soybean liposome containing phenolic extracts showed two peaks (Fig. 4). The occurrence of the second peak indicative of more structured systems, suggests that the phenolic extracts are interposed between the chains of phospholipid bilayer and gives a better flowability compared with the DSC results (Table 2). DSC and XRD analysis revealed the crystalline nature of the phenolic extracts within the liposome, which indicated better solubility in aqueous medium. The X-ray diffraction data confirm that freezedried liposomes are highly amorphous structure, as shown by the diffractograms in Fig. 4. This is a clear indication that they are more suitable for a successfully step of rehydrating as amorphous structures are known to be easier to rehydrate than crystalline arrangements (Kikuchi, Yamauchi, \& Hirota, 1991, Alves \& Santana, 2004, Yokota \& Pine 2012).

\subsection{Release profile}

Fig. 5 shows the release profile of phenolic extracts from S-RL and SSL. For the PBS medium ( $\mathrm{pH} \mathrm{7)}$ a controlled release of phenolic extracts was observed. On the other hand, in Tris- $\mathrm{HCl}(\mathrm{pH} 2)$, the amout of phenolic extracts released from both S-RL and S-SL was very low. These results indicate that both liposomes presented a pH-dependent release profile being able to release the phenolics extracts in a $\mathrm{pH}$ near the intestinal conditions.

In order to evaluate the release mechanism of phenolic compounds from liposomes in PBS, the experimental results were fitted to Fick's second law (Eq. (4)) and LSM (Eq. (6)). For both systems the LSM showed a fitting with a good description of the experimental data indicating that the release mechanism is governed by both Fickian and Case II transport, in this case with one relaxation phenomena (Table 3). Table 3 presents the results of regression analysis for LSM, showing that this model adequately describes the experimental data (moderate regression quality, $R^{2}>0.78$ ) and all parameters were estimated with 


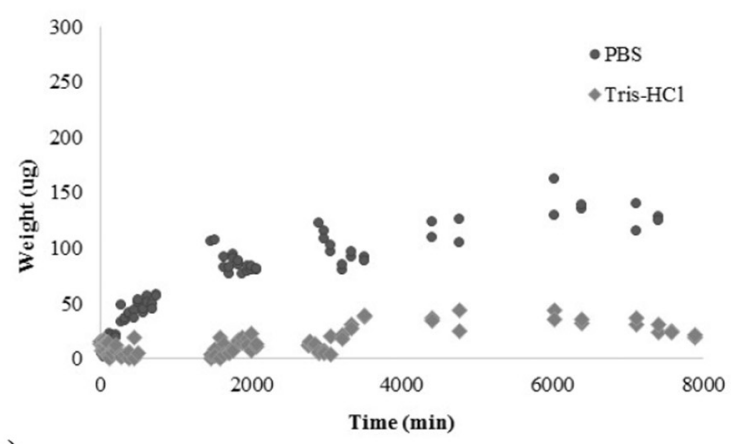

a)

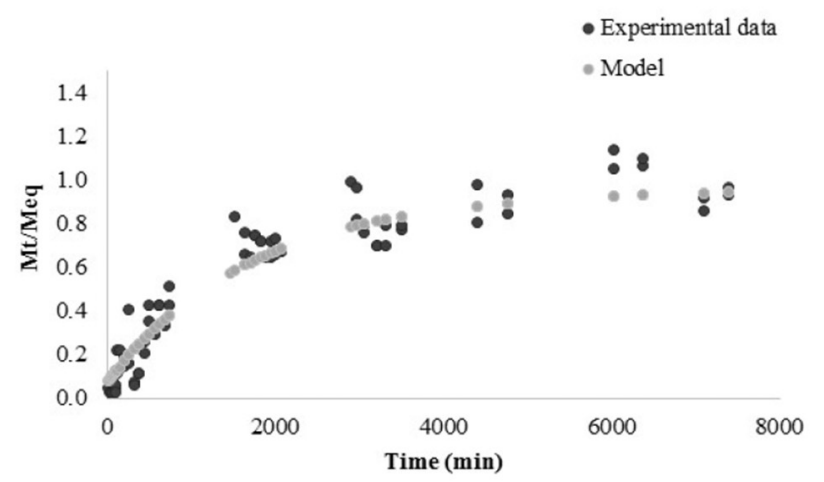

c)

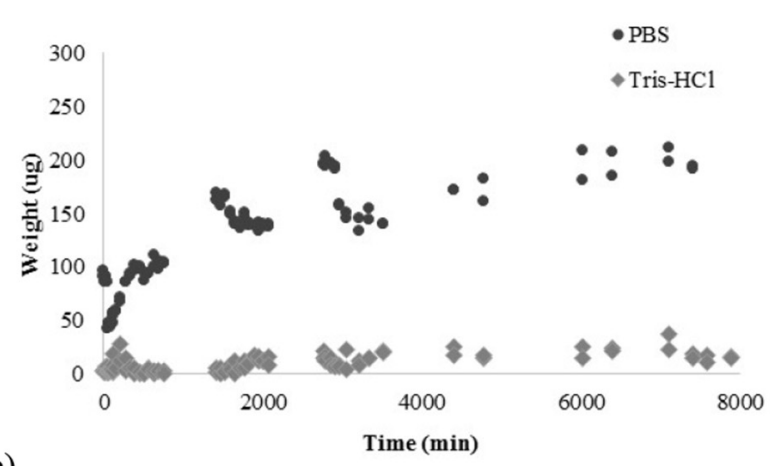

b)

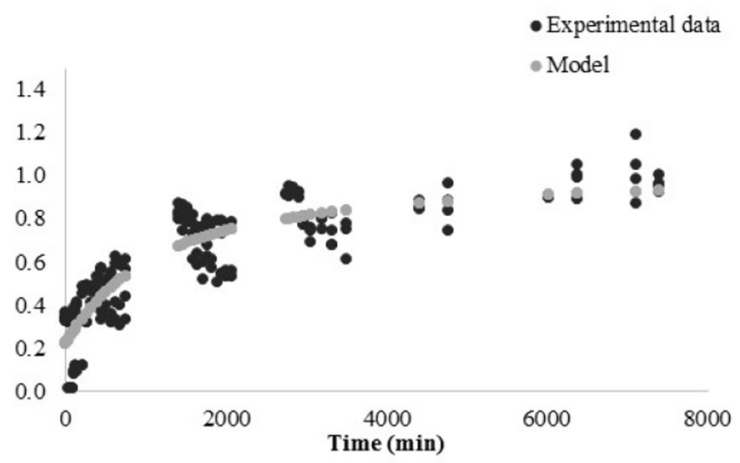

d)

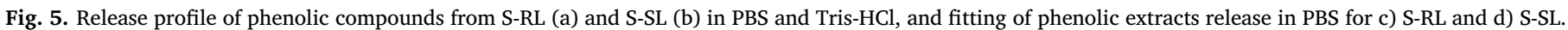

good precision. Also, differences were observed in the transport mechanisms of liposomes. The parameter $X$ (Fick's diffusion contribution to the total release from different liposomes $\left(M_{\infty, F} / M_{t}\right)$ ) indicates a different governing phenomenon: $X<0.5$ for S-RL and $X>0.5$ for S$\mathrm{SL}$, which suggests that relaxation is the governing phenomenon for SRL, and Fick's diffusion is the main release mechanism for S-SL. Also, the relaxation rate constant $\left(k_{R}\right)$ was higher for S-RL, supporting this hypothesis (Table 3). Overall, the total amount release in PBS $(\mathrm{pH}=7)$ was 19 and $125 \mu \mathrm{g}$ to S-SL and S-RL, respectively and in Tris-HCl $(\mathrm{pH}=2)$ the values obtained were 15 and $22 \mu \mathrm{g}$ to S-SL and S-RL, respectively.

These differences in the release profile can be explained through the lecithin matrices that contain phospholipids, which differentiates the liposomes, once lecithin is composed of a set of phosphatides extracted from soybean oil and rice, and the latter has the largest source of phospholipids when compared to soybeans (Machado, de Assis, Machado, \& de Souza-Soares, 2014; Orlandelli, 2008). According to Muller et al. (2002), producing a less ordered solid lipid matrix is a prerequisite for the stability and release of encapsulated bioactives, since the mobility of bioactives in lipid matrix can be controlled by their physical state. Generally, the bioactive is fixed between the fatty acid chains or between the imperfections of lipid crystals (Weiss et al., 2008).

\subsection{In vitro gastrointestinal digestion}

Liposomes can play an important role in the transport and delivery of bioactive agents in the gastrointestinal system and thus, it is important to understand how liposomes are affected during digestion in the human gut. To do that, it is possible to follow liposomes behaviour (e.g. size, $\zeta$-potential and morphology) when submitted to a digestion simulation using an in vitro dynamic gastrointestinal system. Also the release of FFA and bioaccessability can be accessed.

\subsubsection{Size and morphology during digestion}

Results showed that liposomes' size increased during in vitro digestion (Table 4), which is in accordance with previously reported literature (Bonnaire, Helgason, Decker, Weiss, \& Mcclements, 2008; Mun, Decker, \& McClements, 2007; Mun, Decker, Park, Weiss, \& McClements, 2006). Early at stomach stage, the particle size of liposomes significantly increased in all systems, being this increase more accentuated for liposomes containing phenolic compounds. In fact, S-RL and S-SL were unstable under gastric conditions, exhibiting a large increase in particle size and PDI (indicating extensive droplet aggregation), probably due to the interaction of phenolic compounds and phospholipids with enzymes.

Under intestinal conditions, from duodenum stage, the particle size of RL, SL, S-RL and S-SL significantly increased, probably due to particle

Table 3

Results of fitting the Linear Superposition Model (LSM) $(i=1)$ to experimental data of PLL release. Evaluation of the quality of the regression on the basis of RMSE and $R^{2}$. Estimates' precision is evaluated using the SHW\% (in parenthesis).

\begin{tabular}{llllll}
\hline Sample & RMSE & $R^{2}$ & $X$ & $K_{F}\left(\min ^{-1}\right)$ & $K_{R}\left(\mathrm{~min}^{-1}\right)$ \\
\hline S-RL & 3.38 & 0.894 & $0.17(50.64 \%)$ & $5.7 \times 10^{-3}(179.72 \%)$ & $3.6 \times 10^{-2}(12.94 \%)$ \\
S-SL & 3.90 & 0.787 & $0.55(20.20 \%)$ & $2.2 \times 10^{-4}(41.99 \%)$ & $1.2 \times 10^{-3}(25.36 \%)$
\end{tabular}

RMSE: squared root mean square error; $R^{2}$ : quality of the regression; X: fraction of compound released by Fickian transport; $K_{F}$ : Fickian diffusion rate constant; $K_{R}$ : relaxation rate constant. 
Table 4

Size distribution (SD), polydispersity index (PDI), and suspension stability as measured by $\zeta$-potential of liposomes subjected to the in vitro gastro intestinal system.

\begin{tabular}{|c|c|c|c|}
\hline Sample & $\mathrm{SD}(\mathrm{nm})$ & PDI & $\zeta$-potential (mV) \\
\hline \multicolumn{4}{|l|}{ Stomach } \\
\hline RL & $466.68 \pm 18.49^{c}$ & $0.513 \pm 0.039^{\mathrm{d}}$ & $-8.95 \pm 1.80^{c}$ \\
\hline S-RL & $487.05 \pm 1.34^{c}$ & $0.596 \pm 0.060^{c}$ & $-10,09 \pm 0.64^{\mathrm{b}}$ \\
\hline SL & $517.25 \pm 5.15^{\mathrm{b}}$ & $0.873 \pm 0.040^{\mathrm{a}}$ & $-12.1 \pm 1.44^{\mathrm{a}}$ \\
\hline S-SL & $672.55 \pm 16.33^{\mathrm{a}}$ & $0.675 \pm 0.120^{\mathrm{b}}$ & $-10.28 \pm 0.38^{\mathrm{b}}$ \\
\hline \multicolumn{4}{|c|}{ Duodenum } \\
\hline $\mathrm{RL}$ & $3209.00 \pm 24.00^{\mathrm{a}}$ & $0.495 \pm 0.240^{c}$ & $-18 ., 90 \pm 1.53^{b}$ \\
\hline S-RL & $2634.00 \pm 15.56^{\mathrm{b}}$ & $0.456 \pm 0.034^{c}$ & $-15.20 \pm 0.20^{c}$ \\
\hline SL & $1021.50 \pm 9.50^{c}$ & $0.634 \pm 0.050^{\mathrm{a}}$ & $-15.1 \pm 2.35^{c}$ \\
\hline S-SL & $2655.00 \pm 8.48^{\mathrm{b}}$ & $0.604 \pm 0.090^{b}$ & $-26.75 \pm 0.21^{\mathrm{a}}$ \\
\hline \multicolumn{4}{|c|}{ Jejunum filtrate } \\
\hline $\mathrm{RL}$ & $592.00 \pm 31.06^{b}$ & $0.644 \pm 0.075^{b}$ & $-12.9 \pm 0.40^{b}$ \\
\hline S-RL & $554.40 \pm 20.51^{b}$ & $0.652 \pm 0.080^{b}$ & $-21.5 \pm 0.26^{\mathrm{a}}$ \\
\hline SL & $447.95 \pm 5.15^{c}$ & $0.430 \pm 0.010^{c}$ & $-8.55 \pm 0.49^{c}$ \\
\hline S-SL & $681.80 \pm 17.25^{\mathrm{a}}$ & $0.775 \pm 0.080^{\mathrm{a}}$ & $-22.43 \pm 0.72^{\mathrm{a}}$ \\
\hline \multicolumn{4}{|c|}{ Ileum filtrate } \\
\hline $\mathrm{RL}$ & $152.75 \pm 11.25^{\mathrm{d}}$ & $0.297 \pm 0.020^{\mathrm{d}}$ & $-4.66 \pm 0.68^{d}$ \\
\hline S-RL & $263.90 \pm 3.95^{c}$ & $0.462 \pm 0.010^{c}$ & $-26.5 \pm 2.83^{b}$ \\
\hline SL & $284.70 \pm 2.16^{b}$ & $0.533 \pm 0.140^{b}$ & $-9.87 \pm 1.07^{c}$ \\
\hline S-SL & $418.40 \pm 14.26^{a}$ & $0.643 \pm 0.038^{a}$ & $-34.8 \pm 2.64^{\mathrm{a}}$ \\
\hline \multicolumn{4}{|c|}{ Ileum delivery } \\
\hline $\mathrm{RL}$ & $1185.79 \pm 33.08^{b}$ & $0.711 \pm 0.045^{c}$ & $7.88 \pm 0.13^{d}$ \\
\hline S-RL & $734.25 \pm 1.45^{c}$ & $0.822 \pm 0.180^{\mathrm{a}}$ & $-20.5 \pm 0.60^{b}$ \\
\hline SL & $1203.5 \pm 13.5^{b}$ & $0.791 \pm 0.074^{\mathrm{b}}$ & $-14.6 \pm 1.03^{c}$ \\
\hline S-SL & $1289.50 \pm 9.19^{a}$ & $0.703 \pm 0.011^{\mathrm{d}}$ & $-29.60 \pm 1.08^{\mathrm{a}}$ \\
\hline
\end{tabular}

Means in the same column with the different superscripts (a, b, c, d) are statistically differrent $(\mathrm{p}<0.05)$.

aggregation (flocculation and coalescence of liposomes). At these digestion stages, bile salts and lipase molecules can access and hydrolyze the phospholipids, producing free fatty acids (FFA) and glycerol, at the droplet surfaces. These surface-active products of digestion are ineffective at stabilizing liposome against coalescence, which can explain the instability of liposomes (i.e. high particle sizes and PDI). As expected, jejunal and ileal filtrates (i.e. the fraction absorbed at jejunum and ileum compartments, respectively) exhibited particle sizes significantly $(\mathrm{p}<0.05)$ lower than the ileal delivery (i.e. fraction that is not absorbed in the small intestine). It should be noted that the dynamic light scattering used has a size limitation, once it is only suitable for the measurement of particle diameters up to few microns (aprox. $6 \mu \mathrm{m}$ ), therefore, the results obtained for some samples should be carrefull analyzed.

Most of the liposomes exhibited rough and dense surfaces but integer structures (Fig. 2). However, after digestion in the dynamic gastro-intestinal system, liposomes were irregular in shape, with fewer remaining intact liposomes (results not shown), and liposomal membrane was obviously damaged.

Liu et al. (2013) studied the stability of lactoferrin (LF) loaded liposomes before and during digestion. These liposomes were prepared from milk fat globule membrane-derived phospholipids and exhibited an average diameter of of $1369 \pm 109 \mathrm{~nm}$ (before digestion), with a polydispersity index (PDI) of $0.28 \pm 0.02$. However, the average diameter decreased to about $500 \mathrm{~nm}$ when the liposomes were mixed with simulated gastric fluid (SGF) in the absence of pepsin and did not change significantly during digestion for $2 \mathrm{~h}$ in SGF in the presence of pepsin. The average diameter of the LF-loaded liposomes increased markedly in the first $1 \mathrm{~min}$ of digestion in simulated intestinal fluid (SIF) (to about $2389 \pm 215 \mathrm{~nm}$; PDI $=0.69 \pm 0.11$ ), with a gradual decrease thereafter. Therefore, it was found that the liposomes produced in this study, with rice and soybean lecithin, obtained an increase in particle size due to enzymatic hydrolysis.

\subsection{2. $\zeta$-potential}

$\zeta$-potential was measured to determine changes in the surface charge of the liposomes during digestion in the gastrointestinal conditions (i.e. presence of $\mathrm{pH}$ gradients, enzymes and bile salts). Significant differences $(p>.05)$ were observed between $\zeta$-potential values of liposomes at the subsequent stages of digestion process (Tables 1 and 4). It was observed that the initial charge of the particles was negative, and their interfacial composition changed during digestion. In fact, during the digestion process, the addition of various salts takes place, the stomach $\mathrm{pH}$ decreases to values around 2 , followed by an increase to values around 7.0 in the intestine. Regarding the effect of digestion on liposomes' droplets, it was observed that at early stomach stage, the electrical charge of liposomes changed due to changes in solution conditions ( $\mathrm{pH}$ and ionic strength) or adsorption of charged species from gastric electrolyte solution on liposome surface (Hur, Lim, Decker, \& McClements, 2009). Under duodenal conditions, all liposomes became negatively charged, which suggests adsorption of anionic species (e.g. free fatty acids, bile salts or lipase) on liposome surface, or adsorption of small negatively charged ions from the small intestinal electrolyte solution (Tokle, Deecker, \& McClements, 2012).

Liu et al. (2013) also found changes in the $\zeta$-potential of liposomes containing LF before and after gastrointestinal digestion. These authors obtained a $\zeta$-potential of $-13.0 \pm 0.4 \mathrm{mV}$ for LF-loaded liposomes before digestion, but during digestion, in SGF the $\zeta$-potential of the LFloaded liposomes presented a value of $+9.2 \pm 1.0 \mathrm{mV}$ in the absence of pepsin and zero in the presence of pepsin. In SIF, the $\zeta$-potential of the LF-loaded liposomes was $-44.2 \pm 0.4 \mathrm{mV}$ in the absence of pancreatic lipase and no obvious changes were observed during digestion in SIF containing pancreatic lipase.

\subsubsection{Free fatty acids}

The release of free fatty acids (FFA) shows the extent of lipid hydrolysis in the in vitro gastrointestinal system. The solubility of FFA is considered a fundamental step in digestion and absorption of fats, once lipids are hydrophobic, thus poorly soluble in the aqueous medium of the digestive tract. Therefore, the FFAs content is an indicative of the stability of liposomal phospholipids once the release of FFAs from the digested liposomes confirm the lipolysis of the liposomal membrane. The FFA release rate of liposome phospholipids is a useful indicator of the integrity of liposomes (Liu et al., 2015). Being so, the lipolysis of the bilayers of S-RL, S-SL, RL and SL under gastrointestinal conditions were quantitated by determining the release of FFA (Fig. 6). These results indicate that the phospholipids in liposomes were partially hydrolyzed by pancreatic lipase promoted by the bile salts which increase lipase activity during lipolysis (Singh \& Ye, 2013). In fact, bile salts are one of the agents that affect the liposome structure during intestinal digestion (Kensil \& Dennis, 1981). Bile salts act as detergents, enabling the

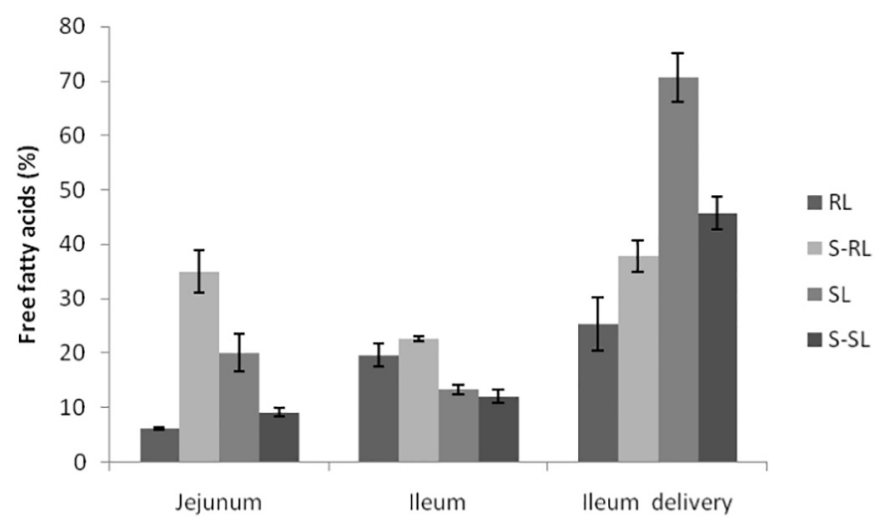

Fig. 6. Release of free fatty acids after in vitro gastrointestinal digestion of rice liposome (RL), rice liposome with phenolic extracts (S-RL), soy liposome (SL) and soy liposome with phenolic extracts (S-SL). 
micelles formation, therefore, they are essential for the phospholipids solubilization during the digestive process (Hermida, Sabes-Xaman, \& Barnadas-Rodriguez, 2014). Phosphatidylcholines are rapidly hydrolyzed by pancreatic enzymes to yield equimolar mixtures of their monoacyl equivalents and fatty acids. Thus, the hydrolysis of phospholipids at the level of ester bonds yields lysophospholipids and free fatty acids. This degenerative chemical process is strongly affected by temperature and $\mathrm{pH}$ of the medium, occuring to a lesser extent at lower temperatures and neutral $\mathrm{pH}$. At an early stage, the hydrolysis does not affect the structure of liposomes, but modifies other properties significantly, especially the membrane permeability. However, at a later stage, the integrity of liposome is destabilized since the free fatty acids and lysophospholipids may act as detergents and thus initiate dissolution of the membrane which terminates with its breakdown (Birru et al., 2014; New, 1990). Similar results were observed by Liu et al. (2015), who found that the liposome membrane was damaged during simulated intestinal fluid digestion, releasing the FFAs.

From the results can be verified that a great part of the FFA remained in the ileum delivery, therefore they were not absorbed. Is also possible to observe that the FFA that remained in the ileum delivery is higher for soy lecithin giving the indication of a lower absorption of SL when compared with the RL.

\subsubsection{Bioaccessibility of phenolic extracts}

The bioaccessibility was evaluated at the end of simulated intestinal digestion for the free phenolics extracts and for S-RL and S-SL. Bioaccessibility is defined as the amount of compound ingested which is available for intestinal absorption, that subsists at the various stages of digestion becoming an absorbable compound (Cilla et al., 2012). Results showed an increase of the bioaccessibility values from 31.65 to 35.83 and $45.89 \%$ when the phenolic extracts are in the free form, and encapsulated in SL and RL liposomes, respectively. The bioacessibility values are in agreement with FFA values obtained for the soy liposomes, where was observed a lower absorption in the jejunum and ileum when compared with rice liposomes.

These results are in agreement with the values obtained for other nanosystems loaded with resveratrol (a type of polyphenol) where has been showed that the bioaccessibility increases from 60 to $73 \%$ when the revesratol is in the free form and encapsulated in biopolymer nanoparticles (Davidov-Pardo, Pérez-Ciordia, Marín-Arroyo, \& McClements, 2015).

\section{Conclusion}

Liposomes were successufly produced using rice and soybean lecithin, and used for the encapsulation of phenolic extracts from Spirulina microalgae. Liposomes showed to be influenced by the incorporation of phenolic extracts in their structure, as confirmed by the increase of size distribution and zeta potential, and changes in the FTIR spectra and thermal pattern. Liposomes allowed the protection of phenolic compounds during the gastric step of the digestion so that the release of the bioactive compounds occurred in the small intestine. The liposomes can be applied in foods, showing good characteristics for the encapsulation of bioactive compounds.

\section{Acknowledgements}

The authors thank FURG and, FAPERGS, RS, Brasil; Science Without Borders -CNPq, CSF, Brasil; University of Minho, Braga, Portugal; and Fundação para a Ciência Tecnologia (FCT, POPH-QREN and FSE Portugal). The author Ana C. Pinheiro is recipient of a fellowship from the Fundação para a Ciência Tecnologia (FCT, Portugal) through grant SFRH/BPD/101181/2014.

\section{References}

Alves, G. P., \& Santana, M. H. A. (2004). Phospholipid dry powder produced by spray drying processing: Structural, thermodynamic, and physical properties. Powder Technology, 145(6), 139-148.

Assis, L. M., Machado, A. R., Motta, A. S., Costa, J. A. V., \& Souza-Soares, L. A. (2014) Development and characterization of nanovesicles containing phenolic compounds of microalgae spirulina strain LEB-18 and Chlorella pyrenoidosa. Advances in Materials Physics and Chemistry, 4(1), 6-12.

Attama, A. A., \& Muller-Goymann, C. C. (2008). Effect of beeswax modification on the lipid matrix and solid lipid nanoparticle crystallinity. Colloids and Surfaces A: Physicochemical and Engineering Aspects, 315, 189-195.

Bai, C. Q., Peng, H. I., Xiong, H., Liu, Y. Z., Zaoh, I. P., \& Xiao, X. N. (2011). Carboxymethylchitosan-coates, proliposomes contaning coix seed oil: Characterisation, stability and in vitro release evaluation. Food Chemistry, 129, 1695-1702.

Berens, A. R., \& Hopfenberg, H. B. (1978). Diffusion and relaxation in glassy polymer powders. 2. Separation of diffusion and relaxation parameters. Polymer, 19(5), 489-496.

Birru, W. A., Warren, D. B., Ibrahim, A., Williams, H. D., Benameur, H., Porter, C. J. H., Pouton, C. W. (2014). Digestion of phospholipids after secretion of bile into the duodenum changes the phase behavior of bile components. Pharmaceutical Molecular, 11(8), 2825-2834.

Bonnaire, L. S., Helgason, T., Decker, E. A., Weiss, J., \& Mcclements, D. J. (2008) Influence of lipid physical state on the in vitro digestibility of emulsified lipids. Journal of Agricultural and Food Chemistry, 56(10), 3791-3797.

Bourbon, A. I., Pinheiro, A. C., Carneiro-Da-Cunha, M. G., Pereira, R. N., Cerqueira, M. A. \& Vicente, A. A. (2015). Development and characterization of lactoferrin-GMP nanohydrogels: Evaluation of $\mathrm{pH}$, ionic strength and temperature effect. Food Hydrocolloids, 48, 292-300.

Cagnasso, M., Boero, V., Franchini, M. A., \& Chorover, J. (2017). ATR-FTIR studies of phospholipid vesicle interactions with $\alpha-\mathrm{FeOOH}$ and $\alpha-\mathrm{Fe}_{2} \mathrm{O}_{3}$ surfaces. Colloids and Surfaces B: Biointerfaces, 76, 456-467.

Capanoglu, E., Beekwilder, J., Boyacioglu, D., De Vos, R. C., \& Hall, R. D. (2010). The effect of industrial food processing on potentially health-beneficial tomato antioxidants. Critical Reviews in Food Science and Nutrition, 50(10), 919-930.

Caparino, O. A., Tang, K. I., Nindo, C. I., Sablani, S. S., Powers, J. R., \& Fellman, J. K. (2012). Effect of drying methods on the physical properties and microstructures of mango (Philippine"Carabao" var.) powder. Journal of Food Engineering, 111(1), 135-148.

Chanda, H., Das, P., Chakraborty, R., \& Ghosh, A. (2011). Development and evaluation of liposomes of fluconazole. Journal of Pharmaceutical and Biomedical Sciences, 5(27), 1-9.

Cheng, C., Peng, S., Li, Z., Zou, L., Liu, W., \& Liu, C. (2017). Improved bioavailability of curcumin in liposomes prepared using a pH-driven, organic solvent-free, easily scalable process. RSC Advance, 7, 25978-25986.

Cilla, A., Alegría, A., de Ancos, B., Sánchez-Moreno, C., Cano, M. P., Plaza, L., \& Barberá, R. (2012). Bioaccessibility of tocopherols, carotenoids, and ascorbic acid from milkand soy-based fruit beverages: Influence of food matrix and processing. Journal of Agricultural and Food Chemistry, 60(29), 7282-7290.

Colla, L. M., Badiale-Furlong, E., \& Costa, J. A. V. (2007). Antioxidant properties of Spirulina (Arthospira) platensis cultivated under different temperatures and nitrogen regimes. Brazilian Archives of Biology and Technology. 50(1), 161-167.

Davidov-Pardo, G., Pérez-Ciordia, S., Marín-Arroyo, M. A. R., \& McClements, D. J. (2015), Improving resveratrol bioaccessibility using biopolymer nanoparticles and complexes: Impact of protein-carbohydrate Maillard conjugation. Journal of Agriculture and Food Chemistry. 63(15), 3915-3923.

De Lima, V. R., Caro, M. S. B., Munford, M., Desbat, B., Duforc, E., Pasa, A. A., \& Creczynski-Pasa, T. B. (2010). Influence of melatonin on the order of phosphatidylcholine-based membranes. Journal of Pineal Research. 49, 169-175.

Di Cola, E., Grillo, I., \& Ristori, S. (2016). Small angle X-ray and Neutron scattering: Powerful tools for studying the structure of Drug-Loaded Liposomes. Pharmaceutics, $8(2), 10$.

Fang, Z., \& Bhandari, Z. (2010). Encapsulation of polyphenols - A review. Trends in Food Science \& Technology, 1, 510-523.

Frezard, F. (1999). Liposomes: From biophysics to the design of peptide vaccines. Brazilian Journal of Medical and Biological Research, 32, 181-189.

Ghaeni, M., \& Roomiani, L. (2016). Review for application and medicine effects of Spirulina, Microalgae. Journal of Advanced Agricultural Technologies. 3(2), 114-117.

Gutiérrez, M. E., Garcia, A. F., Madariaga, M. A., Sagrista, L., Casado, F. J., \& Mora, M. (2003). Interaction of tocopherols and phenolic compounds with membrane lipid components: Evaluation of their antioxidant activity in a liposomal model system. Life Sciences. 72, 2337-2360.

Hermida, L. G., Sabes-Xaman, I. M., \& Barnadas-Rodriguez, R. (2014). Characteristics and behaviour of liposomes when incubated with natural bile salt extract: Implications for their use as oral drug delivery systems. Soft Matter, 10, 6677-6685.

Hur, S. J., Lim, B. O., Decker, E. A., \& McClements, D. J. (2009). Influence of initial emulsifier type on microstructural changes occurring in emulsified lipids during in vitro digestion. Food Chemistry, 114(1), 253-262.

Jeong, B., Bae, Y. H., \& Kim, S. W. (1999). Thermoreversible gelation of PEG-PLGA-PEG triblock copolymer aqueous solutions. Macromolecules, 32, 7064-7069.

Jeong, S. H., Park, J. H., \& Park, K. (2007). Formulation of questions about oral and parenteral delivery systems for lipid-based. In K. M. Wasan (Ed.). Role of Lipid Excipients in oral and parenteral drug administration Modified (pp. 32). Hoboken: WileyInterscience. 
Kan-Zhi, L., Jackson, M., Sowa, M. G., Haisong, J., Dixon, I. M. C., \& Mantsch, H. H. (1996). Modification of the extracellular matrix following myocardial infarction monitored by FTIR spectroscopy. Biochimica et Biophysica Acta, 1315, 73-77.

Kensil, C. R., \& Dennis, E. A. (1981). Alkaline hydrolysis of phospholipids in model membranes and the dependence on their state of aggregation. Biochemistry, 20(21), 6079-6085.

Kikuchi, H., Yamauchi, H., \& Hirota, S. (1991). A method of spray drying for mass production of liposomes. Chemical \& Pharmaceutical Bulletin. 39(6), 1522.

Kramer, S. D., Jakits-Deiser, C., \& Wunderli-Allenspach, H. (1997). Free fatty acids cause $\mathrm{pH}$ - dependent changes in drug-lipid membrane interactions around physiological pH. Pharmaceutical Research, 14(6), 827-832.

Kramer, S. D., \& Wunderli-Allenspach, H. (1996). The pH-dependence in the partitioning behaviour of (RS)-[3H]-propranolol between MDCK cell lipid vesicles and buffer. Pharmaceutical Research, 13, 1851-1855.

Liu, W., Liu, W. L., Liu, C. M., Liu, J. H., Yang, S. B., Zheng, H. J., ... Song, X. Y. (2011). Medium-chain fatty acid nanoliposomes for easy energy supply. Nutrition, 27, 700-706.

Liu, W., Ye, A., Liu, W., Liu, C., Han, J., \& Singh, H. (2015). Behaviour of liposomes loaded with bovine serum albumin during in vitro digestion. Food Chemistry, 175, $16-24$.

Liu, W., Ye, A., Liu, W., Liu, C., \& Singh, H. (2013). Stability during in vitro digestion of lactoferrin-loaded liposomes prepared from milk fat globule membrane-derived phospholipids. Journal of Dairy Science. 9(4), 2061-2070.

Luo, Y., Teng, Z., \& Wang, Q. (2012). Development of zein nanoparticles coated with carboxymethyl chitosan for encapsulation and controlled release of vitamin $\mathrm{D}_{3}$. Journal Agricultural and Food Chemistry. 60(3), 836-843.

Luo, Y., Zhang, B., Whent, M., Yu, L. L., \& Wang, Q. (2011). Preparation and characterization of zein/chitosan complex for encapsulation of $\alpha$-tocopherol, and its in vitro controlled release study. Colloids and Surfaces B: Biointerfaces. 85(2), 145-152.

Machado, A. R. (2016). Encapsulação de compostos fenólicos extraídos de microalgas submetidos ao sistema gastro intestinal in vitro / Adriana Rodrigues Machado. $267 \mathrm{f}$. Tese (doutorado) - Universidade Federal do Rio Grande - FURG. Rio Grande: Programa de Pós-Graduação em Engenharia e Ciência de Alimentos.

Machado, A. R., Assis, L. M., Costa, J. A. V., Badiale-Furlong, E., Motta, A. S., Micheletto, Y. M. S., \& Souza-Soares, L. A. (2014). Application of sonication and mixing for nanoencapsulation of the cyanobacterium Spirulina platensis in liposomes. International Food Research Journal. 21(6), 2201-2206.

Machado, A. R., Cerqueira, M. A., Vicente, A. A., \& Souza-Soares, L. A. (2015). Avaliação de dois métodos para a determinação da eficiência de encapsulação de compostos fenólicos em lipossomas. Congresso de ciência e tecnologia de alimentos, CYTAL 2015 AATA, Buenos Aires.

Machado, A. R., de Assis, L. M., Machado, M. I. R., \& de Souza-Soares, L. A. (2014). Importance of lecithin for encapsulation processes. African Journal of Food Science. 8(4), 176-183.

Machado, A. R., Graça, C. S., Assis, L. M. D., \& Souza-Soares, L. A. D. (2017). Uma abordagem sobre caracterização e avaliação do potencial antioxidante de extratos fenólicos de microalgas Spirulina sp. LEB-18 e Chlorella pyrenoidosa. Revista de Ciências Agrárias, 40(1), 264-278.

Manrique-Moreno, M., Howe, J., Suwalsky, M., Garidel, P., \& Brandenburg, K. (2010). Physicochemical interaction study of non-steroidal anti-inflammatory drugs with dimyristoylphosphatidylethanolamine liposomes. Letters in Drug Design \& Discovery. 7, $50-56$.

Mantovani, R. A., Pinheiro, A. C., Vicente, A. A., \& Cunha, R. L. (2017). In vitro digestion of oil-in-water emulsions stabilized by whey protein nanofibrils. Food Research International. 99, 790-798.

Mehnert, W., \& Mäder, K. (2001). Solid lipid nanoparticles. Production, characterization and applications. Advanced Drug Delivery Reviews, 47, 165-196.

Menon, P., Teo, Y. Y., \& Misran, M. (2015). Preparation and characterization of liposomes coated with DEAE- Dextran. Colloids and Surfaces A: Physicochemical and Engineering Aspects. 481, 345-350.

Mertins, O., Sebben, M., Schneider, P. H., Pohlmann, A. R., \& Silveira, N. P. (2008). Caracterização da pureza de fosfatidilcolina da soja através de RMN de $1 \mathrm{H}$ e de 31P. Quimica Nova. 31(7), 1856-1859.

Mira, N. V. M., Barros, R. M. C., Schiocchet, M. A., Noldin, J. A., \& Lanfer-Marquez, U. M. (2008). Extração, análise e distribuição dos ácidos fenólicos em genótipos pigmentados e não pigmentados de arroz (Oryza sativa L.). Ciência e Tecnologia de Alimentos, 28, 994-1002.

Mishra, A., Ram, S., \& Ghosh, G. (2009). Dynamic light scattering and optical absorption in biological nanofluids of gold nanoparticles in poly(vinyl pyrrolidone) molecules. Journal of Physical Chemistry C. 113(17), 6976-6982.

Morais, H. A., Barbosa, C. M. S., Delvivo, F. M., Mansur, H. S., Oliveira, M. C., \& Silvestre, M. P. C. (2003). Estabilidade e avaliação sensorial de lipossomas contendo hidrolisados de caseína. Brazilian Journal Food Technology. 6(2), 213-220.

Morais, M. G., \& Costa, J. A. V. (2008). Perfil de Ácidos graxos de microalgas cultivadas com dióxido de carbono. Ciência e Agrotecnologia. 32(4), 1245-1251.

Muller, R. H., Radtke, M., \& Wissing, S. A. (2002). Solid lipid nanoparticle (SLN) and nanostructures lipid carriers (NLC) in cosmetic and dermatological preparations. Advanced Drug Delivery Reviews. 54(1), S131-S155.

Mun, S., Decker, E. A., \& McClements, D. J. (2007). Influence of emulsifier type on in vitro digestibility of lipid droplets by pancreatic lipase. Food Research International. 40, 770-781.

Mun, S., Decker, E. A., Park, Y., Weiss, J., \& McClements, D. J. (2006). Influence of interfacial composition on in vitro digestibility of emulsified lipids. Food Biophysics International. 1, 21-29.

New, R. R. C. (1990). Liposomes - A practical approach. New York: Oxford University Press.

Nuhu, A. A. (2013). Spirulina (Arthrospira): an important source of nutritional and medicinal compounds. Journal of Marine Biology325636. https://doi.org/10.1155/ 2013/325636 (8 pages).

Orlandelli, M. C. F. S. (2008). In S. P. Campinas (Ed.). Desacidificação do OFA atraves do processo de extração liquido-liquido descontinuo utilizando alcoois (pp. 78). Universidade Estadual de Campinas, Faculdade de Engenharia Química Master Theses.

Pagnussatt, F. A., de Lima, V. R., Dora, C. L., Costa, J. A. V., Putaux, J. L., \& BadialeFurlong, E. (2016). Assessment of the encapsulation effect of phenolic compounds from Spirulina sp. LEB-18 on their antifusarium activities. Food Chemistry. 211, 616-623.

Pamunuwa, G., Karunaratne, V., \& Karunaratne, D. (2016). Effect of lipid composition on in vitro release and skin deposition of curcumin encapsulated liposomes. Journal of Nanomaterials4535790. https://doi.org/10.1155/2016/4535790 9 pages.

Pamunuwa, K. M. G. K., Bandara, C. J., Karunaratne, V., \& Karunaratne, D. N. (2015) Optimization of a liposomal delivery system for the highly antioxidant methanol extract of stem-bark of Schumacheria castaneifolia Vahl. Journal of Chemical and Pharmaceutical Research. 7(4), 1236-1245.

Parisi, A. S., Younes, S., Reinehr, C. O., \& Colla, L. M. (2009). Avaliação da atividade antibacteriana da microalga Spirulina platensis. Revista de Ciências Farmacêuticas Básica e Aplicada, 30(3), 297-301.

Pinheiro, A. C., Bourbon, A. I., Cerqueira, M. A., Maricato, E., Nunes, C., Coimbra, M. A., \& Vicente, A. A. (2015). Chitosan/fucoidan multilayer nanocapsules as a vehicle for controlled release of bioactive compounds. Carbohydrate Polymers. 115(1-9).

Pinheiro, A. C., Bourbon, A. I., Medeiros, B. G.d. S., da Silva, I. H. M., da Silva, M. C. H., Carneiro Da Cunha, M. G., ... Vicente, A. A. (2012). Interactions k-Carrageenan and chitosan in nanolayered coatings-Structural and transport properties. Carbohydrate Polymers, 87(2), 1081-1090.

Pinheiro, A. C., Coimbra, M. A., \& Vicente, A. A. (2016). In vitro behaviour of curcumin nanoemulsions stabilized by biopolymer emulsifiers: Effect of interfacial composition. Food Hydrocolloids, 52, 460-467.

Pinheiro, A. C., Lad, M., Silva, H. D., Coimbra, M. A., Boland, M., \& Vicente, A. A. (2013). Unravelling the behavior os curcumin nanoemulsions during in vitro digestion: Effect of the surface charge. Soft Matter, 9(11), 3147-3154.

Pinsirodom, P. (2005). Lipase assays. In R. E. Wrolstad (Ed.). Handbook of food: Analytical chemistry (pp. 371-383). Hobokn, NJ: Wiley.

Pourali, O., Asghari, F. S., \& Yoshida, H. (2010). Production of phenolic compounds from rice bran biomass under subcritical water conditions. Chemical Engineering Journal, $160,259-266$.

Priprem, A., Watanatorn, J., Sutthiparinyanont, S., Phachonpai, W., \& Muchimapura, S. (2008). Anxiety and Cognitive Effects of Quercetin Liposomes in Rats. Nanomedicine: Nanotechnology, Biology and Medicine, 4(1), 70-78.

Pyne, P. K., Bhattacharjee, P., \& Srivastav, P. P. (2017). Microalgae (Spirulina Platensis) and its bioactive molecules: Review. Indian Journal of Nutrition. 4(2), 160.

Reis, P., Raab, T., Chuat, J., Leser, M., Miller, R., Watzke, H., \& Holmberg, K. (2008). Influence of surfactants on lípase fat digestion in a model gastro-intestinal system. Food Biophysics, 3(4), 370-381.

Ribani, M., Bottoli, C. B. G., Collins, C. H., Jardim, I. C. S. F., \& Melo, L. F. C. (2004), Validação em métodos cromatográficos e eletroforéticos. Química Nova. 27(5), 771-780.

Saija, A., Bonina, F., Trombetta, D., Montenegro, L., Smeriglio, P., \& Castelli, F. (1995). Flavonoid-biomembrane interactions: A calorimetric study on dipalmitoylphosphatidylcholine vesicles. International Journal of Pharmaceutics, 124, 1-8.

Schmidt, C. G., Gonçalves, L. M., Prietto, L., Hackbart, H., \& Furlong, E. B. (2014). Antioxidant activity and enzyme inhibition of phenolic acids from fermented rice bran with fungus Rizhopus oryzae. Food Chemistry. 146, 371-377.

Severino, P., Pinho, S. C., Souto, E. B., \& Santana, M. H. A. (2011). Polymorphism, crystallinity and hydrophilic-hydrophobic balance of stearic acid and stearic acid capric/ caprylic triglyceride matrices for production of stable nanoparticles. Colloids and Surface B: Biointerfaces. 86(1), 125-130.

Silva, H. D., Cerqueira, M. A., \& Vicente, A. A. (2012). Nanoemulsions for food applications: Development and characterization. Food and Bioprocess Technology. 5(3), 854-867.

Singh, H. (2016). Nanotechnology applications in functional foods; opportunities and challenges. Preventive Nutrition and Food Science. 21(1), 1-8.

Singh, H., \& Ye, A. (2013). Structural and biochemical factors affecting the digestion of protein-stabilized emulsions. Current Opinion in Colloid \& Interface Science. 18(4), 360-370.

Sotiroudis, T. G., \& Sotiroudis, G. T. (2013). Health aspects of Spirulina (Arthrospira) microalga food. Journal of the Serbian. Chemical Society. 78(3), 395-405.

Souza, M. M., Recart, V. M., Rocha, M., Cipolatti, E. P., \& Badiale-Furlong, E. (2009). Estudo das condições de extração de compostos fenólicos de cebola (Allium cepa L.) Revista Instituto Adolfo Lutz, 68(2), 192-200.

Souza, T. D., Prietto, L., Souza, M. M., \& Furlong, E. B. (2015). Profile, antioxidant potential, and applicability of phenolic compounds extracted from Spirulina platensis. African Journal of Biotechnology, 14(41), 2903-2909.

Szoka, F., \& Papahadjopoulos, D. (1978). Procedure for preparation of liposomes with large internal aqueous space and high capture by reverse-phase evaporation. Proceedings of the National Academy of Sciences of the United States of America. 75. Proceedings of the National Academy of Sciences of the United States of America (pp. 4194-4198).

Takahashi, S., Uechi, K., Takara, M., Asikin, Y., \& Wada, K. (2009). Evaluation of an oral carrier system in rats: Bioavailability and antioxidant properties of liposome-encapsulated curcumin. Journal of Agricultural and Food Chemistry. 57(19), 9141-9146.

Tan, C., Xue, J., Abbas, S., Feng, B., Zhang, X., \& Xia, S. (2014). Liposome as a delivery system for carotenoids: Comparative antioxidant activity of carotenoids as measured by ferric reducing antioxidant power, DPPH assay and lipid peroxidation. Journal of 
Agricultural and Food Chemistry. 62(28), 6726-6735.

Tokle, T., Decker, E., \& McClements, D. J. (2012). Utilization of interfacial engineering to produce novel emulsion properties: Pre-mixed lactoferrin/ $\beta$-lactoglobulin protein emulsifiers. Food Research International, 49(1), 46-72.

Toyran, N., \& Severcan, F. (2003). Competitive effect of vitamin $\mathrm{D}_{2}$ and $\mathrm{Ca}^{2+}$ on phospholipid model membranes: An FTIR study. Chemistry and Physics of Lipids. 123(2), 165-176.

Weiss, J., Decker, E. A., McClements, D. J., Kristbergsson, K., Helgason, T., \& Awad, T. (2008). Solid lipid nanoparticles as delivery systms for bioactive food components. Food Biophysics, 3, 146-154.

Xia, S., \& Xu, S. (2005). Ferrous sulfate liposomes: Preparation, stability and application in fluid milk. Food Research International, 38, 289-296.

Yokota, D., Moraes, M., \& Pinho, S. C. (2012). Caracterização dos lipossomas liofilizados produzidos com lecitina de soja não purificada: um estudo de caso de hidrolisado de caseína microencapsulação. Brazilian Journal of Chemical Engineering. 29(2), 325-335.

Zavareze, E. R., Telles, A. C., Mello, S. L. E. H., Rocha, M., Colussi, R., Assis, M. L., .. Prentice-Hernández, C. (2014). Production and characterization of encapsulated antioxidative protein hydrolysates from Whitemouth croaker (Micropogonias furnieri) muscle and by product. LWT-Food Science and Technology. 59(2), 841-848.

Zhou, G. F., Sun, Y., Xin, H., Zhang, Y., Li, Z., \& Xu, Z. (2004). In vivo antitumor and immun, modulation activities of different molecular weight lambda-carrageenans from Chrondus Ocellatus. Pharmacology Research. 50, 47-53.

Zhou, W., Liu, W., Zou, L., Liu, W., Liu, C., Liang, R., \& Chen, J. (2014). Storage stability and skin permeation of vitamin C liposomes improved by pectin coating. Colloids and Surfaces B: Biointerfaces, 117, 330-337. 